\title{
Geologic map of the northern hemisphere of Vesta based on Dawn Framing Camera (FC) images
}

\author{
Ottaviano Ruesch ${ }^{\mathrm{a}, *}$, Harald Hiesinger ${ }^{\mathrm{a}}$, David T. Blewett ${ }^{\mathrm{b}}$, David A. Williams ${ }^{\mathrm{c}}$, Debra Buczkowski ${ }^{\mathrm{b}}$, \\ Jennifer Scully ${ }^{\mathrm{d}}$, R. Aileen Yingst ${ }^{\mathrm{e}}$, Thomas Roatsch ${ }^{\mathrm{f}}$, Frank Preusker ${ }^{\mathrm{f}}$, Ralf Jaumann ${ }^{\mathrm{f}}$, \\ Christopher T. Russell ${ }^{\mathrm{d}}$, Carol A. Raymond ${ }^{\mathrm{g}}$
}

\author{
${ }^{a}$ Institut für Planetologie, Westfälische Wilhelms-Universität Münster, 48149 Münster, Germany \\ b Johns Hopkins University, Applied Physics Laboratory, Laurel, MD 20723, United States \\ 'Arizona State University, Tempe, AZ 85287-1404, United States \\ d University of California, Los Angeles, Institute of Geophysics and Planetary Physics, Dept. of Earth and Space Science, Los Angeles, CA 90095-1567, United States \\ e Planetary Science Institute, Tucson, AZ 85719, United States \\ ${ }^{\mathrm{f}}$ German Aerospace Center (DLR), Rutherfordstraße 2, Berlin, Germany \\ Jet Propulsion Laboratory, California Institute of Technology, Pasadena, CA 91109, United States
}

\section{A R T I C L E I N F O}

Article history:

Available online $\mathrm{xxxx}$

\section{Keywords:}

Asteroid Vesta

Asteroids, surfaces

Geological processes

\begin{abstract}
A B S T R A C T
The Dawn Framing Camera (FC) has imaged the northern hemisphere of the Asteroid (4) Vesta at high spatial resolution and coverage. This study represents the first investigation of the overall geology of the northern hemisphere $\left(22-90^{\circ} \mathrm{N}\right.$, quadrangles $\mathrm{Av}-1,2,3,4$ and 5) using these unique Dawn mission observations. We have compiled a morphologic map and performed crater size-frequency distribution (CSFD) measurements to date the geologic units. The hemisphere is characterized by a heavily cratered surface with a few highly subdued basins up to $\sim 200 \mathrm{~km}$ in diameter. The most widespread unit is a plateau (cratered highland unit), similar to, although of lower elevation than the equatorial Vestalia Terra plateau. Large-scale troughs and ridges have regionally affected the surface. Between $\sim 180^{\circ} \mathrm{E}$ and $\sim 270^{\circ} \mathrm{E}$, these tectonic features are well developed and related to the south pole Veneneia impact (Saturnalia Fossae trough unit), elsewhere on the hemisphere they are rare and subdued (Saturnalia Fossae cratered unit). In these pre-Rheasilvia units we observed an unexpectedly high frequency of impact craters up to $\sim 10 \mathrm{~km}$ in diameter, whose formation could in part be related to the Rheasilvia basin-forming event. The Rheasilvia impact has potentially affected the northern hemisphere also with S-N small-scale lineations, but without covering it with an ejecta blanket. Post-Rheasilvia impact craters are small ( $<60 \mathrm{~km}$ in diameter) and show a wide range of degradation states due to impact gardening and mass wasting processes. Where fresh, they display an ejecta blanket, bright rays and slope movements on walls. In places, crater rims have dark material ejecta and some crater floors are covered by ponded material interpreted as impact melt.
\end{abstract}

(c) 2014 Elsevier Inc. All rights reserved.

\section{Introduction}

The Dawn mission is dedicated to exploring and comprehensively characterizing two large asteroids, Vesta and Ceres (Veverka et al., 1989; Farquhar et al., 2002; Rayman et al., 2006; Russell et al., 2007; Russell and Raymond, 2011). The Dawn spacecraft orbited the asteroid Vesta for over one year, from July 2011 to September 2012, and imaged the surface at high spatial resolution (Russell et al., 2012). Previous space missions specifically dedicated to

* Corresponding author. Address: Institut für Planetologie, Wilhelm-Klemm Str. 10, 48149 Münster, Germany.

E-mail address: ottaviano.ruesch@uni-muenster.de (O. Ruesch). asteroids, NEAR Shoemaker (e.g., Veverka et al., 2001) and Hayabusa (e.g., Yano et al., 2006) have studied small bodies a few hundred meters (Itokawa) to several tens of kilometers (Eros) in size. Unlike these small bodies, Vesta is one of the more massive and intact Main Belt asteroids (McCord, 2006), with a differentiated interior (Russell et al., 2012) and may possibly be a survivor of the original protoplanets (e.g., Russell et al., 2012).

Previous missions to asteroids have provided insight into the geology of low gravity, irregularly shaped and airless small bodies (e.g., Sullivan et al., 2002). Some of the morphologies and processes occurring on coherent bodies such as Lutetia (e.g., Thomas et al., 2012), Eros (e.g., Robinson et al., 2002; Thomas et al., 2002), Phobos 
(e.g., Thomas, 1979), Ida (e.g., Sullivan et al., 1996) and Gaspra (e.g., Carr et al., 1994) might be expected to also occur on Vesta. Impact cratering is the dominant process on all of these bodies, with the resulting morphologies being variable: the surface might only display bowl-shaped craters with a wide range of degradation states (e.g., Ida) or be globally affected by complex topographic structures (e.g., Lutetia) (e.g., Thomas et al., 1999, 2012). As a result of impact cratering, the surfaces of planetary bodies possess a pervasive regolith on the order of $10-100 \mathrm{~m}$ deep, approaching $1 \mathrm{~km}$ for large bodies (e.g., Hausen and Wilkening, 1982). This regolith is modified and redistributed by slope processes as shown by (i) several landforms that indicate mass wasting (see Sullivan et al., 2002 for a review) and (ii) albedo features, which suggest superficial downslope motion (e.g., Thomas et al., 2002). Furthermore, impact melt is produced by impacts in uncertain quantities (e.g., Keil et al., 1997; Williams et al., in press; Goguen et al., 1978; Sullivan et al., 1996). Some morphologies could indicate particular processes, such as flat deposits following equipotential surfaces, i.e., "ponded deposits" on Eros (Robinson et al., 2001). Grooves, troughs or ridges have also been observed on small bodies (e.g., Thomas and Prockter, 2010). On the basis of their patterns, their origin can be related to impacts or to global fractures related to the formation and evolution of the asteroid (e.g., Horstman and Melosh, 1989; Prockter et al., 2002; Buczkowski et al., 2008). Finally, the uppermost material of the regolith consists of a very thin layer that is subject to optical maturation with increasing exposure age of the surface (e.g., Clark et al., 2001; Chapman, 1996).

Vesta differs from the small bodies that have previously been visited by spacecraft mainly due to its larger size and its shape derived from viscous relaxation (e.g., Thomas, 1989). On the other hand, Vesta is much smaller than the terrestrial planets and the Moon. One of the efforts of the Dawn Science Team has been to investigate the geology of asteroid Vesta through geologic mapping. Geologic mapping attempts to decipher the evolution of a given body (e.g., Coradini et al., 2011; Greeley and Batson, 1990), to provide the context for the spectrally derived composition of the surface (e.g., De Sanctis et al., 2012a), and, in the case of Vesta, to understand the possible link with achondrite meteorites (e.g., McSween et al., 2011; Mayne et al., 2010; Sykes and Vilas, 2001). The first Dawn observations of Vesta's shape and morphology were reported by Jaumann et al. (2012). These were global-scale observations obtained in the first phase of the mission and limited to latitudes south of $30^{\circ} \mathrm{N}$. The northern hemisphere was observed in later phases of the mission when it was sufficiently illuminated. The mapping of Vesta's surface has been subdivided into 15 quadrangles (Roatsch et al., 2012; Williams et al., this issue-a), which conform with the quadrangle scheme proposed by Greeley and Batson (1990). For each of the quadrangles, a geologic map was produced at the scale of $1: 500,000$. Here we focus on the northern hemisphere (quadrangles Av-1, Av-2, Av-3, Av-4 and Av-5), within $22-90^{\circ} \mathrm{N}$ and $0-360^{\circ} \mathrm{E}$. Additional studies, for example of tectonic features observed in the northern hemisphere, are presented in Scully et al. (2014). A study of the effects of the south pole basins antipodes (Rheasilvia and Veneneia) is presented in Blewett et al. (2014).

In summary, this study aims to address the following questions: (1) What are the morphologic characteristics of the northern hemisphere? (2) What are the stratigraphic relationships of the identified geologic units? (3) How old/young are the terrains? (4) What is the geologic history and evolution of the northern hemisphere?

\section{Datasets and methods}

Among others techniques, photogeologic mapping uses surface morphology and appearance (i.e., roughness, texture) to identify discrete surfaces within a given area. These surfaces correspond to three-dimensional rock units (e.g., Wilhelms et al., 1987). We have identified and mapped units and linear structures in images and derived products of the Framing Camera (FC) onboard the Dawn spacecraft. These observations were acquired during three mission phases corresponding to orbits with different altitudes: an early High Altitude Mapping Orbit (HAMO-1, altitude of $685 \mathrm{~km}$ ), a Low Altitude Mapping Orbit (LAMO, altitude of $200 \mathrm{~km}$ ), and a later High Altitude Mapping Orbit (HAMO-2, altitude of $685 \mathrm{~km}$ ) (Russell et al., 2006; Russell and Raymond, 2011). FC images were acquired in a frame mode through a panchromatic clear filter and seven narrow-band color filters (Sierks et al., 2011). Clear filter raw images were calibrated, converted to radiometric units and ortho-rectified (Schröder et al., 2013a). From these images several mosaics were produced (Roatsch et al., 2012; Sierks et al., 2011). A mosaic was derived from each mission phase, differing in spatial resolution and illumination conditions. A mosaic with a pixel scale of $20-25 \mathrm{~m} /$ pixel was derived from LAMO images and covers the study area from $22^{\circ} \mathrm{N}$ to $40-50^{\circ} \mathrm{N}$. A mosaic with a pixel scale of $70 \mathrm{~m} /$ pixel derived from the HAMO-2, covers the entire map area. The HAMO-2 data were obtained later in the mission, after the LAMO, when illumination conditions were more favorable for the observation of the northern areas. However, because solar incidence angles in the northern hemisphere remained high at the time of HAMO-2 and the presence of topographic highs (i.e., rims of craters), shadows are present, increasing in size and frequency toward the North Pole. Images acquired during the departure phase (RC4 phase, altitude of $\sim 6000 \mathrm{~km}$ ) with a pixel scale of $\sim 560 \mathrm{~m} /$ pixel were also used to fill gaps in areas not illuminated during earlier mission phases. Note that the figures created with these latter images present some mosaic artifacts related to different illumination conditions. In order to highlight the morphologic features on a local scale (e.g., $\sim 10 \mathrm{~km}$ ), a linear stretch of the mosaics was applied using 2.5 times the standard deviation of the scene (e.g., $\sim 10 \mathrm{~km}$ wide). Such modification has been applied to all the figures presented in this paper. To reveal morphologies within shadowed areas, an additional linear stretch was applied only to the shadowed portion of the image (Fig. 8).

Topographic investigations were carried out on Digital Terrain Models (DTM) derived from stereo-photogrammetric and photoclinometry methods (Sierks et al., 2011; Gaskell, 2012; Preusker et al., 2012). The stereo-photogrammetric method relies on the geometric parallax and matching of two to five FC panchromatic images. The resolution achieved with HAMO-1 data is $93 \mathrm{~m} /$ pixel with a vertical uncertainty of $\pm 30 \mathrm{~m}$ (Jaumann et al., 2012). Photoclinometry relies on photometric assumptions. The vertical resolution of the latter DTM is approximately $50 \mathrm{~m} /$ pixel (Gaskell et al., 2008; Gaskell, 2012). Both DTMs are referenced to a two-axis ellipsoid with radii of $285 \times 229 \mathrm{~km}$ (hereafter called datum: Jaumann et al., 2012). Further investigations of the surface features were done by studying the albedo of the surface, which gives insight into surface properties (e.g., composition, grain size; McCord et al., 2012; Reddy et al., 2012a). We used a normal visual albedo map produced by Schröder et al. (2013b) with HAMO-2 clear filter images. The map was calculated by employing the Akimov law and a polynomial function as average phase function (Schröder et al., 2013b).

A relative stratigraphy and absolute model ages for the morphologic units were derived from crater size-frequency distribution (CSFD) measurements. CSFDs were performed on selected counting areas within morphologic units. For the count areas particular attention was paid to homogeneity in surface texture and illumination. Surfaces with high slopes were disregarded because craters might be modified by topographic effects. Obvious secondary craters (i.e., chains, clusters) and endogenic crater pits were omitted. A detailed description of the methodology is given by Hiesinger 
et al. (2000). Elevation-induced distortions on map-projected images might be critical on Vesta. Thus, the measurements of crater diameters and areas were corrected with the formulas presented in Kneissl et al. (this issue). Uncertainties in the measurements of crater diameters on Vesta are due to (i) "asymmetric" elongated rim craters that are formed by impacts on slopes (Krohn et al., submitted for publication) and (ii) basins (defined here as impacts larger than $100 \mathrm{~km}$ ), which are morphologically highly degraded and recognized only on the basis of topography, making it difficult to precisely measure their diameters. The obtained CSFD measurements were analyzed in cumulative distribution plots (Crater Analysis Techniques Working Group, Arvidson et al., 1978) with the production function and lunar-like chronology of Schmedemann et al. (in preparation). The production function is based on the lunar cratering record and calculated with crater scaling laws (e.g., crater diameter to/from impactor diameter). The chronology function is calculated using a vestan impact probability of Main Belt asteroids and the lunar chronology (Schmedemann et al., in preparation). This method, similar to the chronologies for Mars (e.g., Ivanov, 2001; Hartmann and Neukum, 2001), is briefly reviewed in Williams et al. (2014a). The lunar chronology itself relies on radiometrically dated samples and crater counts on the lunar surface (e.g., Stöffler and Ryder, 2001; Neukum et al., 2001; Hiesinger et al., 2012). We have chosen to use these functions rather than the alternative Vesta chronology of O'Brien (in preparation) and production function used by Marchi et al. (2012), and discussed in Williams et al. (2014a). The reason for this choice is that the chronology and production functions of Schmedemann et al. (in preparation) are based on lunar observations (CSFD and lunar samples) scaled to the Vesta conditions, in contrast to a chronology based on Main Belt dynamics (O'Brien, in preparation) and a production function based on a model of the size-frequency distribution of Main Belt objects (Marchi et al., 2012). To allow comparison, however, we analyze our measurements and derive the crater retention age (i.e. number of craters above $\left.1 \mathrm{~km}: N_{\text {cum }}(D \geqslant 1 \mathrm{~km})\right)$ and absolute model ages (AMAs) with both methods.

Studies have shown that crater counting performed on the proximal ejecta blanket of terrestrial planets and on the Moon may be biased due to the presence of self-secondary craters (e.g., Shoemaker et al., 1968; Plescia et al., 2010; Plescia and Robinson, 2011; Zanetti et al., 2013). However, the relative importance of self-secondaries is not fully understood (e.g., Hiesinger et al., 2012). Because it is not always possible to discriminate between a primary crater from a self-secondary crater, the derived age on ejecta blanket can be considered as a maximum age. This effect, however, might be less important for Vesta since it has been predicted that secondary craters on Vesta would form far away from the source crater (e.g., Bierhaus et al., 2012; Schmedemann et al., in preparation). We avoided counting on potential impact melt deposits (e.g., Williams et al., in press) because for such surfaces the target properties influence the diameter of craters formed in the strength regime (e.g., Dundas et al., 2010; van der Bogert et al., 2010, 2013). This effect leads to biased (i.e., younger) ages (e.g., van der Bogert et al., 2010, 2013; Hiesinger et al., 2012).

All the data used in this study were analyzed using a Geographic Information System (ESRI/ArcGIS). CSFD measurements were performed using the CraterTool software of Kneissl et al. (2011) and the CraterStats software of Michael and Neukum (2010). Because the shape of Vesta differs substantially from a sphere, the DTMs and single FC images were also analyzed with the Small Body Mapping Tool software (Kahn et al., 2011), which allows three-dimensional visualization.

The nomenclature of the features in the mapping area reflects the official names endorsed by the International Astronomical
Union. The longitude references used in this paper are in the Claudia system (Russell et al., 2012), which is different from the International Astronomical Union (IAU)-approved coordinate system and different from the Dawn data provided by the Planetary Data System (PDS). The longitudes used here are offset by $-150^{\circ}$ (see also Williams et al., this issue-a).

\section{Global context}

Fig. 1 shows four oblique views of the surface and topography of Vesta. The first three views are centered at a latitude of about $40^{\circ} \mathrm{N}$ and at three different meridians $\left(70^{\circ} \mathrm{E}, 180^{\circ} \mathrm{E}\right.$ and $\left.300^{\circ} \mathrm{E}\right)$. The fourth view depicts an oblique view of the southern hemisphere centered at $40^{\circ} \mathrm{S} / 70^{\circ} \mathrm{E}$. The geology of the southern hemisphere is characterized by the impacts Rheasilvia and Veneneia: a central mound, a circular depression and large scale scarps are present (Jaumann et al., 2012; Schenk et al., 2012). Mass wasting material has accumulated within the basins whereas ejecta material has been distributed and accumulated outside (Schenk et al., 2012; Otto et al., 2013). A unit containing troughs and ridges located at the equator is named the Divalia Fossae Formation and is possibly the result of the Rheasilvia impact (Jaumann et al., 2012; Buczkowski et al., 2012).

The northern hemisphere, on the other hand, is mainly dominated by many smaller impact craters. In Fig. 1a, the different morphology of craters can be observed. Circular topographic lows can be recognized and interpreted as basins, superposed by brighter and fresh appearing younger craters. Furthermore, topographic highs form a sub-circular feature between $0^{\circ} \mathrm{E}$ and $70^{\circ} \mathrm{E}$ that might indicate an additional basin (see also Fig. 4 of Marchi et al., 2012). Fig. 1b illustrates troughs and ridges of the Saturnalia Fossae Formation, which encircles a large fraction of the northern hemisphere. These features are interpreted as the result of the Veneneia impact (Jaumann et al., 2012; Buczkowski et al., 2012). In Fig. 1b, the crater Marcia is visible with its conspicuous and partly dark-toned ejecta material, extending toward the north. Fig. 1c shows how the Saturnalia Fossae features are not restricted to the northern hemisphere, but extend into equatorial regions. The large ridge extending east-west is named Lavinium Dorsum.

\section{Results}

\subsection{Geologic map}

The geologic map is presented in Fig. 2. For better visualization, the quadrangles Av-1, Av-2, Av-3, Av-4 and Av-5 have been merged into a single polar stereographic map at a scale of $1: 500,000$. The map covers an area of $\sim 3.09 \times 10^{5} \mathrm{~km}^{2}$. The definition and nomenclature of the map units are based on a broader, global scale geologic map of Vesta by Yingst et al. (2014). The most ubiquitous units are unit $c h$, corresponding to the cratered highlands, unit $S f c$, corresponding to the Saturnalia Fossae cratered material, and unit $S f t$, corresponding to the Saturnalia Fossae troughs material. The contact between the three units is gradational, occurring over a few tens of kilometers. Unit $u c$ corresponds to undifferentiated crater material, and has been subdivided into unit hcm, hummocky crater material, and dicm, distant crater material. Smaller-scale units are lobate crater material, labeled as $l c$, and dark and bright crater material, respectively, called unit $d c$ and $b c$. Associated units are dark and bright crater ray material, units $d c r$ and $b c r$. Units $d l$ and $s$ refer to dark lobate material and smooth material. An additional unit, $c w o$, has been defined to map crater wall outcrops. Linear features have been identified and named following the definition from the global scale map of Yingst et al. (2014). They 

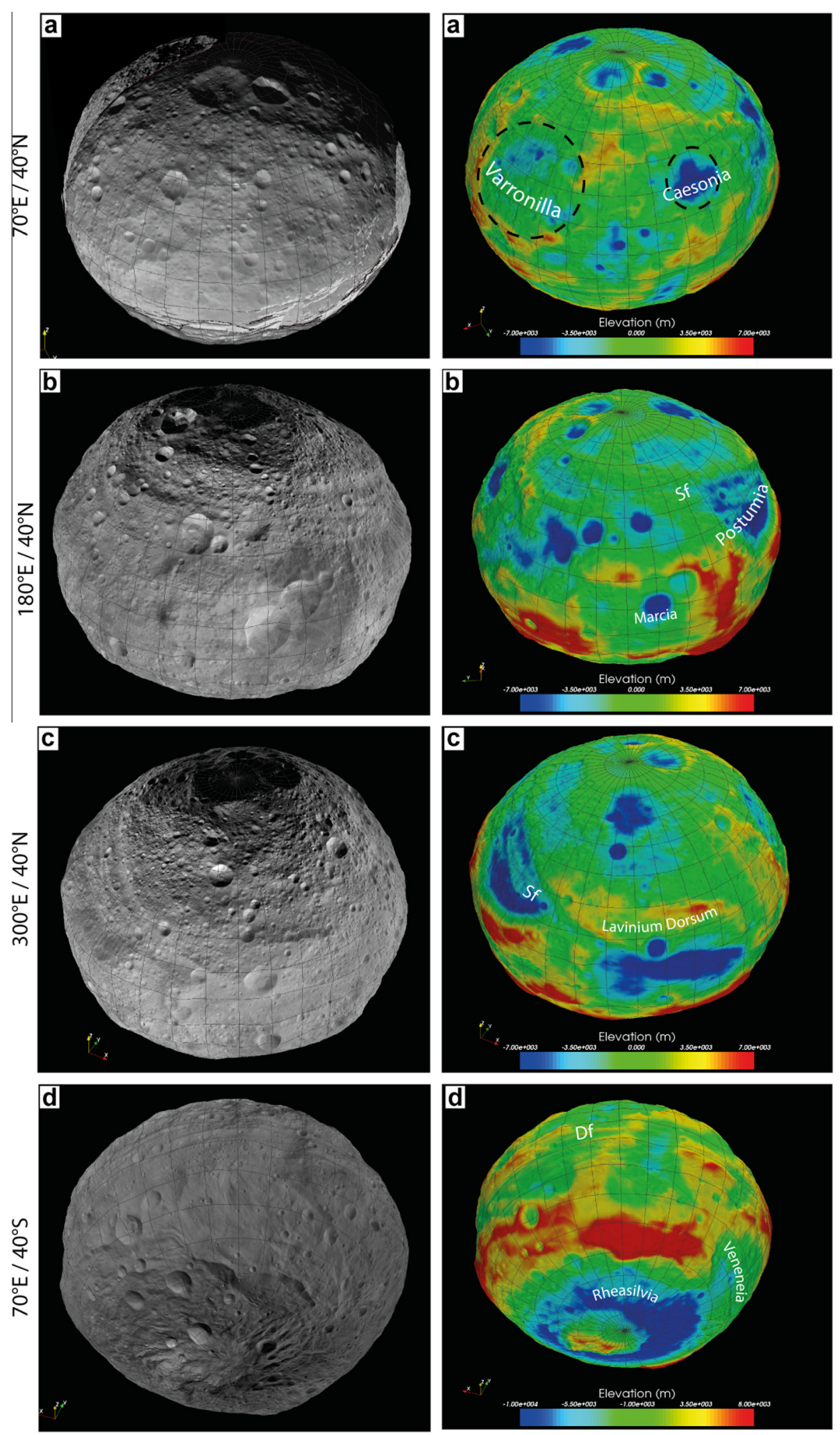

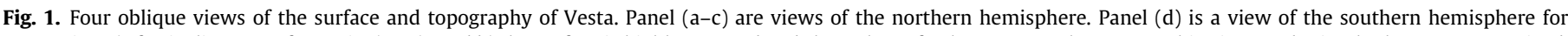

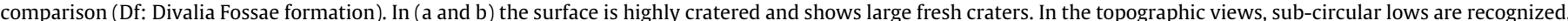

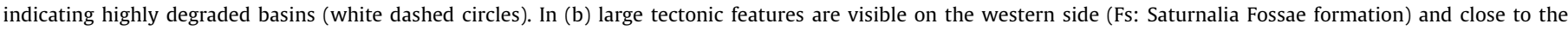
meridian (Lavinium Dorsum). Note that the topographic scale is different for (d).

correspond to troughs and ridges. Smaller scale linear features are referred to as lineations and their trend is schematically mapped. For a detailed mapping and analysis of linear features see Scully et al. (2014).

\subsection{Map units description}

ch - cratered highlands material: This unit is characterized by a high density of impact craters and a lack of large-scale tectonic 


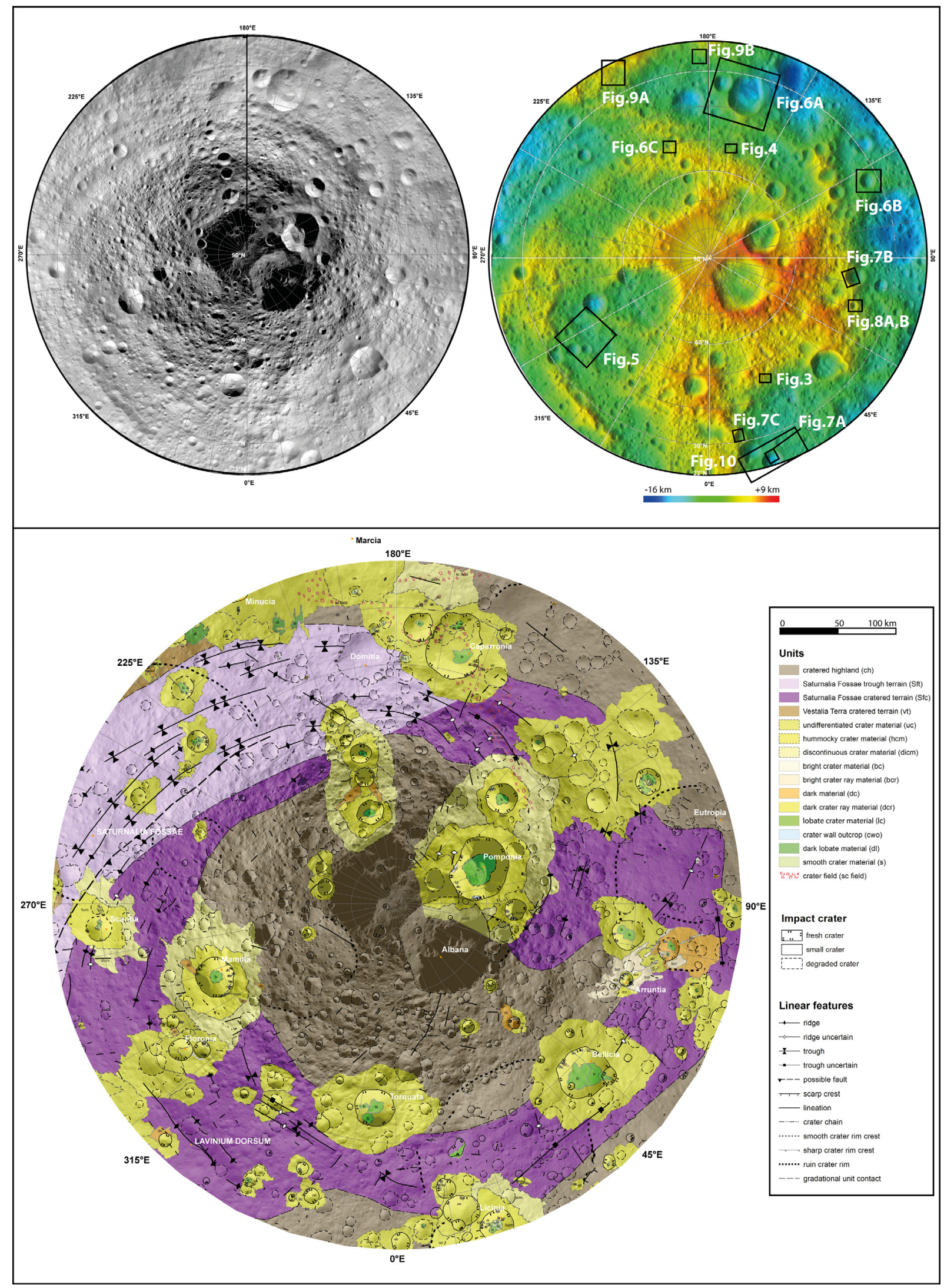

Fig. 2. Top: A Framing Camera mosaic of the study area (left) and a derived topography relative to a reference ellipsoid of $285 \times 229 \mathrm{~km}$ (right) with figure locations. Bottom: Geologic map of the northern hemisphere of Vesta $\left(22-90^{\circ} \mathrm{N}\right.$ and $\left.0-360^{\circ} \mathrm{E}\right)$ in a polar stereographic projection. 
features. Impact craters are mapped as fresh, degraded or small craters. Fresh craters are identified by a circular rim, a sharp rim crest and are simple craters ( $<7 \mathrm{~km}$ in diameter). The spatial resolution of the HAMO-2 mosaic does not allow clear identification of their ejecta blankets. Larger fresh craters usually display a different morphology, with a flat floor or lobate material, and are mapped as a different unit. Degraded craters have an irregular shape, a subdued or absent rim crest and are shallower compared to fresh craters (e.g., Domitia crater). They have superposed impacts and might display a polygonal shape. Small craters have been defined by diameters ranging from $\sim 4$ to $5 \mathrm{~km}$. They display a bowl-like shape and the ejecta blanket as well as the sharpness of the rim crest cannot be discerned at the spatial resolution of the HAMO2 mosaic. A full range of intermediate morphologies between fresh and degraded craters is observed at all sizes.

The surface possesses fine features consisting of sets of lineations (Fig. 3). Lineations occur in the form of ridges and grooves, frequently subdued, on the order of $1.5 \mathrm{~km}$ wide, and with a median length of $4.7 \mathrm{~km}$. Ridges are often sinuous. In some places lineations are recognized only as faint albedo markings or as discontinuous furrows. Lineations occur in sets sharing a common direction. Two (or more) sets might be present in the same scene and show superposition or cross-cutting relationships (Fig. 3). In the study area, several sets of lineations share a common, broad north-south trend. Note that the sketches presented in Fig. 3 and some following figures were produced on a base of LAMO images, and thus contain more visible detail than does the geologic map of Fig. 2.

Beside these lineations, small crater chains or craters exhibiting herringbone patterns are also observed. In some rare locations they show a radial distribution around fresh craters, which are identified as their source crater. In most cases, however, the association of secondary craters with their source crater is non-trivial. This is because of the presence of sets of secondaries from nearby fresh craters, or the presence of lineations of similar appearance. In some places, the rims of ruined basins are identified by a scarp and a smoother surface downslope.

Unit $c h$ is the most ubiquitous unit of the northern hemisphere, covering $35 \%$ of the map area. The most widespread occurrence of the unit is near $40^{\circ} \mathrm{E} / 70^{\circ} \mathrm{N}$ and the topography of the region shows a plateau at an altitude of $0 \mathrm{~km}$ relative to the datum. Smaller occurrences are located at southern latitudes and are the continuation of the unit "cratered highland equatorial" (unit $c h$ ) of Yingst et al. (2014), present at the equator. The contact with the other main units (unit $S f t$, unit $S f c$ ) is gradational.
Interpretation: The full range of morphologies of impact craters, from fresh appearing to highly degraded, indicates a complete range of degradation states. Thus, together with their widespread occurrence, they suggest that the surface was exposed to meteoroid bombardment for an extended period of time. The high density of craters relative to other areas on Vesta suggests that the unit represent one of the oldest terrains of the asteroid. Detailed investigations of the crater density are discussed in Section 4.5. Lineations might be related to surface disturbance/scouring by discontinuous ejecta material, probably from two or more craters. However, we did not find a clear relationship with any specific source crater. Hence, it is possible that the locations of these impacts are outside the mapped area in the northern hemisphere. This would be consistent with the prediction that on a low gravity body the secondary craters form far away from the parent primary (e.g., Bierhaus et al., 2012). Another possible origin of these features might be related to fractures. Cracks in the interior due to impacts could trigger the drainage of mobile regolith into pits and lead to the formation of grooves (Horstmann and Melosh, 1989). This interpretation has been proposed on Phobos, where, however, grooves are considerably narrower (Horstmann and Melosh, 1989). Ridges could either be accumulations of downslope mass movement or be similar to wrinkle ridges/thrust scarps and have a tectonic origin. Note that viewing direction and Sun angle are critical to the detection of lineations (e.g., Murray and Iliffe, 2011), and might create biases. Because of the similar crater morphologies and densities, this unit might be similar to the cratered highland terrain on the Moon, which is built up by interfingering deposits of crater material (e.g., Wilhelms et al., 1987; Hörz et al., 1991). In addition, the smooth appearance at the highest spatial resolution, and the presence of competent outcrops (unit cwo) beneath the surface, suggest that the uppermost part of the unit consist of loose material (i.e., regolith) formed by surface gardening, as a consequence of long-term meteoroid bombardment. An estimation of the depth of this possible regolith is presented in the discussion section.

Sft - Saturnalia Fossae trough material: This unit is characterized by large-scale troughs and ridges named Saturnalia Fossae. It covers $10 \%$ of the map area. On average, ridges are $18 \mathrm{~km}$ in length and occur at an elevation of $\sim-6 \mathrm{~km}$. Single troughs can be traced from a few tens of kilometers to $\sim 200 \mathrm{~km}$ and occur at an elevation of $\sim-9 \mathrm{~km}$.

In addition to large-scale troughs and ridges, small-scale lineations are present. These are more pronounced than the lineations in unit ch and their morphology is variable, ranging from grooves
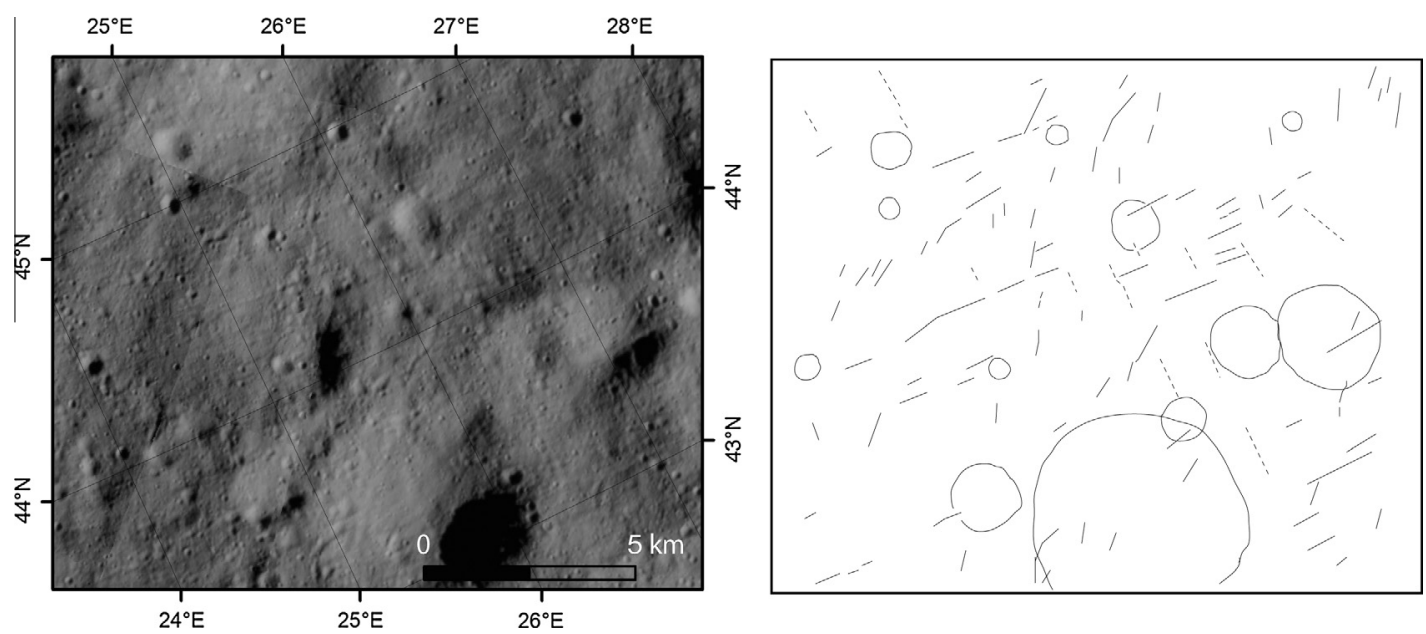

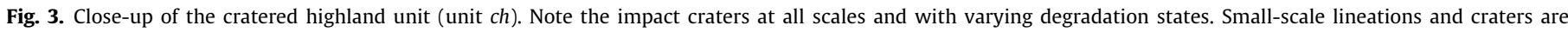
schematically illustrated on the right. Dashed lines indicate more faint lineations. 

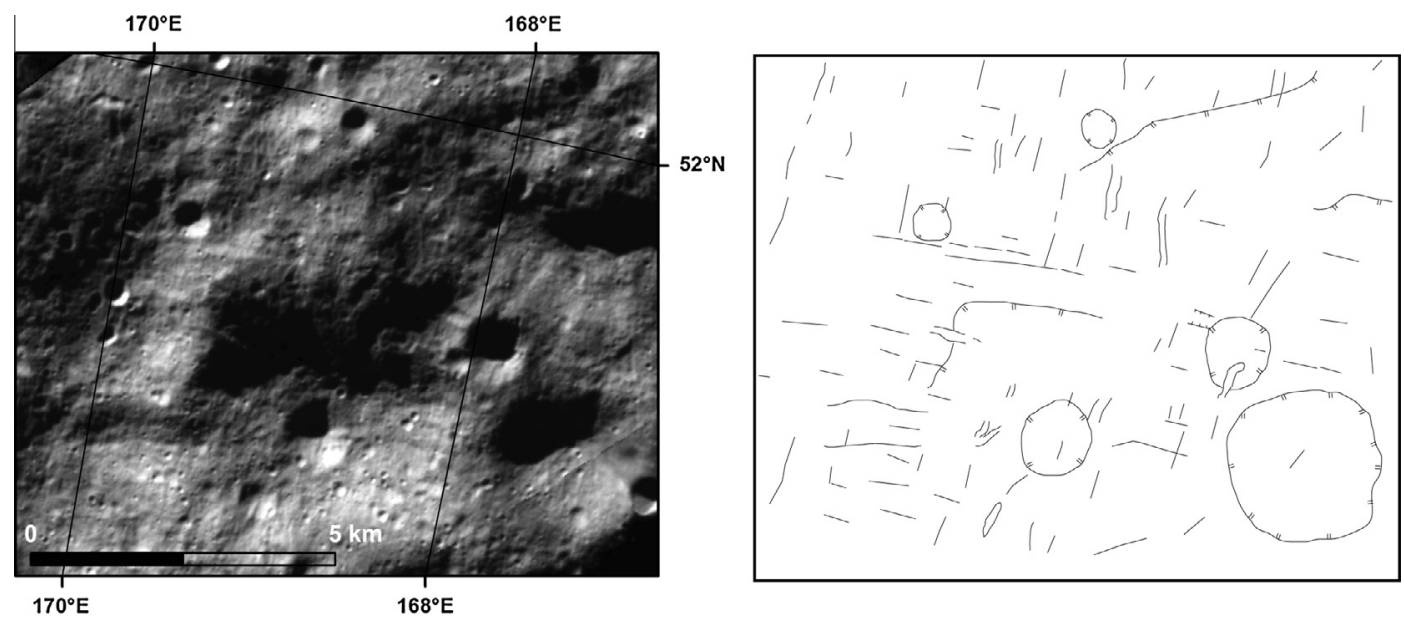

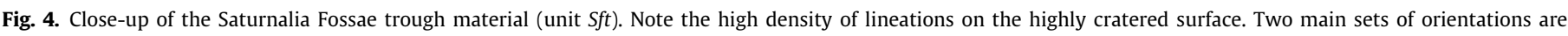
recognized: S-N and E-W. The lineations are in the form of straight/curvilinear ridges and troughs. Map on the right.

and pit crater chains to ridges. Fig. 4a shows a LAMO mosaic closeup of unit Sft and in Fig. 4b the corresponding lineations are mapped. A set of lineations in Fig. $4 \mathrm{~b}$ has an E-W direction, corresponding to the trend observed elsewhere on the unit and parallel to the large-scale ridges/troughs (Scully et al., this issue). Note also the lineations with a perpendicular $(\mathrm{S}-\mathrm{N})$ direction. As with unit $c h$, this unit is highly cratered and exhibits numerous fresh asymmetric craters (Krohn et al., submitted for publication).

Of particular interest for stratigraphic relationships is a ruin basin, the Postumia basin. The basin is defined by a truncated circular topographic depression centered at $30^{\circ} \mathrm{N} / 350^{\circ} \mathrm{E}$ and is approximately $\sim 200 \mathrm{~km}$ in diameter. The circular depression is clearly defined in the south, where it is superimposed on the topographically higher Vestalia Terra (see also Av-9 map). It is truncated by a NE$\mathrm{SW}$ ridge that encompasses the longitudes from $165^{\circ} \mathrm{E}$ to $310^{\circ} \mathrm{E}$. North of the ridge the basin depression is absent. The troughs and ridges of unit Sft cut into the basin and thus postdate the basin forming event.

Interpretation: Unit Sft is interpreted as ancient crustal material, tectonically deformed by the Veneneia impact (Jaumann et al., 2012; Buczkowski et al., 2012). The system of troughs and ridges probably represent horst-graben structures, similar to the Divalia Fossae tectonic system (Buczkowski et al., 2012). The more muted morphology of the Saturnalia Fossae compared to the Divalia Fossae could be the result of the age differences between the two tectonic systems. The NE-SW ridge that truncates the Postumia basin could have formed by a large-scale fault. North of the fault, part of the Postumia basin may have been lifted up by antipodal effects of the Veneneia or Rheasilvia impacts (e.g., Blewett et al., submitted for publication; Bowling et al., 2013). In-depth analyses and a discussion of the tectonic features that characterize unit Sft are presented by Scully et al. (2014). The small-scale lineations represented by E-W grooves and pit crater chains could have a tectonic origin related to the Saturnalia Fossae system. Similar, although smaller, lineations associated with extensional tectonics have been observed on the Moon (e.g., Watters et al., 2012).

Sfc - Saturnalia Fossae cratered material: This unit shares several characteristics of unit $c h$ and, in addition, contains large-scale troughs and ridges. It covers $18 \%$ of the map area. It is distinguished from unit $S f t$ because of less abundant and more subdued troughs and ridges. In addition, a fault plane analysis similar to those performed by Buczkowski et al. (2012) indicates that the troughs and ridges of unit $S f c$ are not co-planar, thus differing from those of unit Sft. The unit shows the least N-S extension near longitude $60^{\circ} \mathrm{E}$ and is characterized by one ridge and an associated trough, both very subdued. At $\sim 120^{\circ} \mathrm{E}$, subdued ridges and troughs have a NNW-SSE orientation and extend to latitudes up to $80^{\circ} \mathrm{N}$. Near $320^{\circ}$, a ridge exists named Lavinim Dorsum, which extends for $\sim 140 \mathrm{~km}$ in an E-W direction, similar to the orientation of Divalia Fossae.

These troughs and ridges are superimposed on degraded basins, as are the basins between Bellicia and Licinia craters, and between Eutropia and Arruntia craters (the Varronilla and Caesonia basins). Like unit $c h$, unit $S f c$ contains several small-scale lineations. The contact with adjacent units is gradational.

Interpretation: This unit is interpreted as ancient crustal material, partly disrupted by troughs and ridges. These linear features could be related to crustal faults. Because fault plane analyses did not revealed a common origin for the troughs, several large impacts could have triggered their formation. In addition, a reactivation of the faults cannot be excluded. Lavinium Dorsum, for example, has a trend similar to that of the Divalia Fossae, and its formation could be associated with the Rheasilvia basin-forming event. Note that some troughs and ridges are mapped as uncertain, as they might be parts of degraded crater rims.

Additional lineations could have formed due to impact shock waves (e.g., Bowling et al., 2013; Jutzi et al., 2013a) or shear stresses following the Rheasilvia-forming event (Scully et al., this issue). Alternatively, and at least for some of the lineations linked to an ejecta ray system, the origin is due to impact scouring across the surface (Scully et al., this issue).

$v t$ - Vestalia Terra material: This unit covers only $3 \%$ of the map and represents the northern extension of the Vestalia Terra material in quadrangle Av-9, described by Buczkowski et al. (2013a). Part of the rim of the Postumia basin occurs within this unit, but no cross-cutting relationship could be determined. This unit is mapped as cratered highlands material (unit $c h$ ) in the global map of Vesta (Yingst et al., 2014). Buczkowski et al. (2013a) showed that the material in Vestalia Terra is distinct from the rest of unit ch, mainly because of its topography. In our map this unit has a gradational contact with unit Sft, occurring over a few tens of kilometers.

Interpretation: The limited extent of this unit within our study area does not allow determination of stratigraphic relationships with the adjacent unit Sft or with the Postumia basin. The characteristics of this unit, mainly found in the equatorial region (Av-9), are discussed in Buczkowski et al. (2013a).

uc - undifferentiated crater material: This unit consists of rim, wall, and floor deposits of fresh and subdued craters (see Fig. 5) and covers $18 \%$ of the map area. The unit is associated with 
fresh/subdued craters as small as $7 \mathrm{~km}$ in diameter. Rims are sparsely cratered. Preexisting craters are still visible and are heavily degraded or partly buried. In some cases, a small number of furrows ( $\sim 700 \mathrm{~m}$ wide, $\sim 15 \mathrm{~km}$ long) are oriented radially to the craters. Furrows ( $\sim 400$ m wide, up to a few kilometers long) are also found outside unit $u c$, sub-radially to the craters. These features sometimes display levees or appear as parallel ridges. The rim crests show a sharp or rounded morphology and alcoves can be present. At HAMO-2 resolution, the walls are usually smooth and homogeneous; only faint undulating scarps can be recognized. Some dark or bright toned areas (unit $d c / b c$ ), as well as subdued spurs (unit cwo) can be present. At LAMO resolution some parts of the walls show intricate braided patterns (e.g., in Caparronia crater). The floors are usually covered by lobate crater material (unit $l c$ ) with a cratered surface. Several craters occur on topographically tilted terrains. These asymmetric craters have a sharp rim crest in the upslope direction (uphill), and very smooth rounded or undefined rim in the downslope direction (downhill). The ejecta material extends further away from the source crater in the downhill direction.

An unusual feature within this unit is a $1 \mathrm{~km}$ wide, $5 \mathrm{~km}$ long furrow with an arc-like shape that incises the ejecta blanket of a fresh crater northeast of Floronia crater (white arrow, Fig. 5). Possible herringbone craters are present nearby. Scarps on the ejecta blanket also occur with a ribbon-like shape. Another unusual feature is present at $230^{\circ} \mathrm{E} / 37^{\circ} \mathrm{N}$, where the unit shows a bright cluster of curvilinear ridges.

Interpretation: Unit $u c$ represents crater and ejecta material of relatively fresh craters. Intricate braided patterns on the wall indicate downslope movement. Subdued rim crests are the result of subsequent small impact bombardment and alcoves might indicate collapse due to seismic shaking by larger meteoroid impacts. Furrows found within the ejecta blanket or close to the crater could be formed by material ejected at a high angle from the source crater (i.e., $>45^{\circ}$ ). The high ejection angle would have prevented the material moving far away from the crater and create secondary craters outside the ejecta blanket (Schmedemann et al., in preparation; Bierhaus et al., 2012). Krohn et al. (2013) mapped the

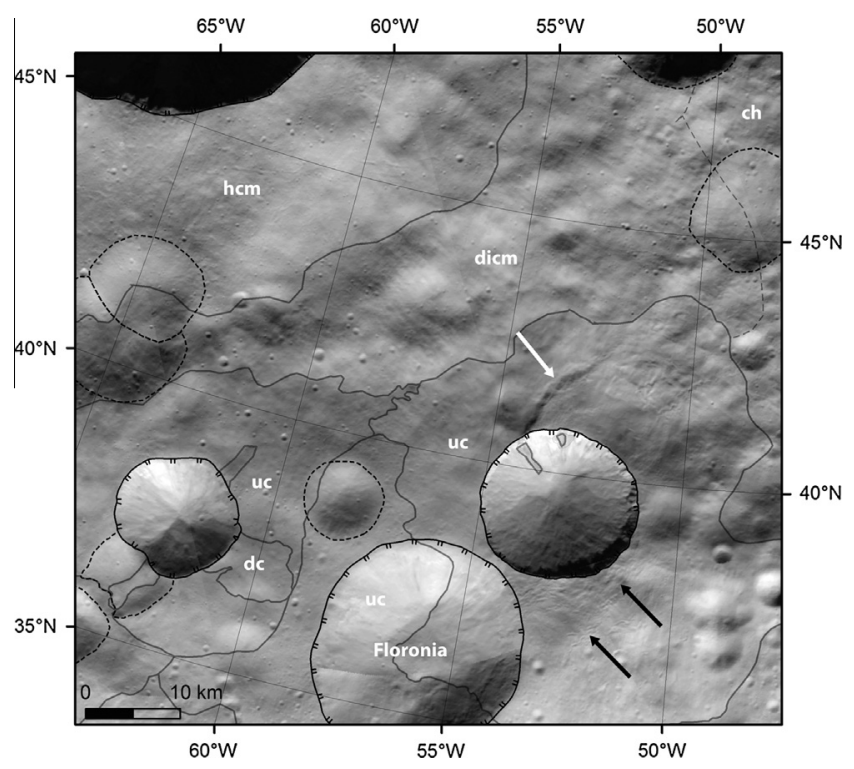

Fig. 5. Region between Mamilia and Floronia craters with extensive crater material units: undifferentiated crater material (unit $u c$ ), hummocky crater material (unit $\mathrm{hcm}$ ) and distant crater material (unit dicm). Note that the boundaries between the units are gradational. White arrow points to a furrow and black arrows show smallscale grooves. distribution of the asymmetric craters on a global scale and discussed their formation on Vesta. They suggested that the downhill rim is a mixture of ejected material and material of the original slope. The latter material would have been deposited by slumping during the impact process (Krohn et al., submitted for publication). Asymmetric craters are not unique to Vesta since they also have been identified in the north polar crater cluster on Lutetia (Thomas et al., 2012). Similarities between asymmetric craters on Lutetia and on Vesta include the rim shape and associated mass-wasting features.

hcm - "hummocky" crater material: This unit consists of rim, wall and floor material of craters fresher than craters of unit $u c$, and covers $7 \%$ of the map area. The rims have a hummocky surface with fewer and smaller craters than unit $u c$ (see Fig. 5). The rim crests are sharper than those of unit $u c$, and in some occasion are cut by well-defined scarps (e.g., Scantia crater). At LAMO resolution, boulders of up to $\sim 400 \mathrm{~m}$ can be identified close to the rim crests. The walls show fresh triangular-faced spurs (unit cwo) with debris fans downslope. Complex albedo patterns are present on the walls with smooth surfaces, i.e., unit $d c / b c$. In some places, the albedo patterns are adjacent to surfaces with intricate braided textures (e.g., Pomponia crater). Lobate crater material (unit $l c$ ) is present on the crater walls and on the crater floors. Where the floor is not entirely covered by lobate crater material (e.g., Licinia crater), a flat, dark-toned deposit is observed, i.e., unit $s$.

Interpretation: Unit hcm represents the inner facies of material from relatively fresh craters, consisting of the crater interior and its continuous ejecta blanket. In some places the outer facies of the crater could be identified, i.e., unit dicm. Unit hcm possibly represents crater material of fresher craters relative to those of unit $u c$. With time, impact gardening modified these morphologies into subdued forms. The latter are mapped as undefined crater material (unit $u c$ ). Further studies are required to establish whether boulder sizes and boulder destruction rates are comparable with boulder measurements on the Moon and on other asteroids (e.g., Bart and Melosh, 2010; Küppers et al., 2012).

dicm - distant crater material: Unit dicm is characterized by curvilinear or rope-like ridges and troughs, oriented radially and subradially to fresh craters. It covers $6 \%$ of the map area. While the surface is generally smooth, the underlying topography is still visible, indicating a relatively thin unit (see Fig. 5). The innermost boundaries close to the source craters correspond to unit $\mathrm{hcm}$. The outermost boundaries can be indistinct and locations are approximate.

Interpretation: Unit dicm represents the outer facies of material of a single relatively fresh crater, consisting of the thinner and discontinuous ejecta material.

lc - lobate crater material: This unit is associated with local relief (e.g., crater walls) and shows an onlap geometry onto adjacent units (Fig. 6). It covers $0.8 \%$ of the map area. The unit is usually found in the topographically low floors of fresh/subdued craters. Features indicating downslope movement are present, such as striations on crater walls. In some locations, the source regions of the material are outcrops or scarps (e.g., Scantia crater). Parts of the crater rim may show alcoves. On some crater floors, several individual lobate materials can be distinguished with clear overlapping contacts. For large ( $>50 \mathrm{~km})$ craters different morphologies are observed, suggesting slumps (e.g., NNE rim of Caparronia crater, Fig. 6a). These morphologies are associated with collapse of parts of crater rims and enlargement of the craters. The two craters visible in Fig. 6a both have a collapsed crater rim in the South. For the largest crater (Caparronia) the collapsed rim is found in the local downslope direction. Note that both craters are partly covered by Marcia ejecta material. Lobate material also displays unusual features in craters located at $30^{\circ} \mathrm{N} / 120^{\circ} \mathrm{E}$ and $50^{\circ} \mathrm{N} / 200^{\circ} \mathrm{E}$, illustrated in Fig. $6 \mathrm{~b}$ and c, respectively. At $30^{\circ} \mathrm{N} / 120^{\circ} \mathrm{E}$ an asymmetric crater 

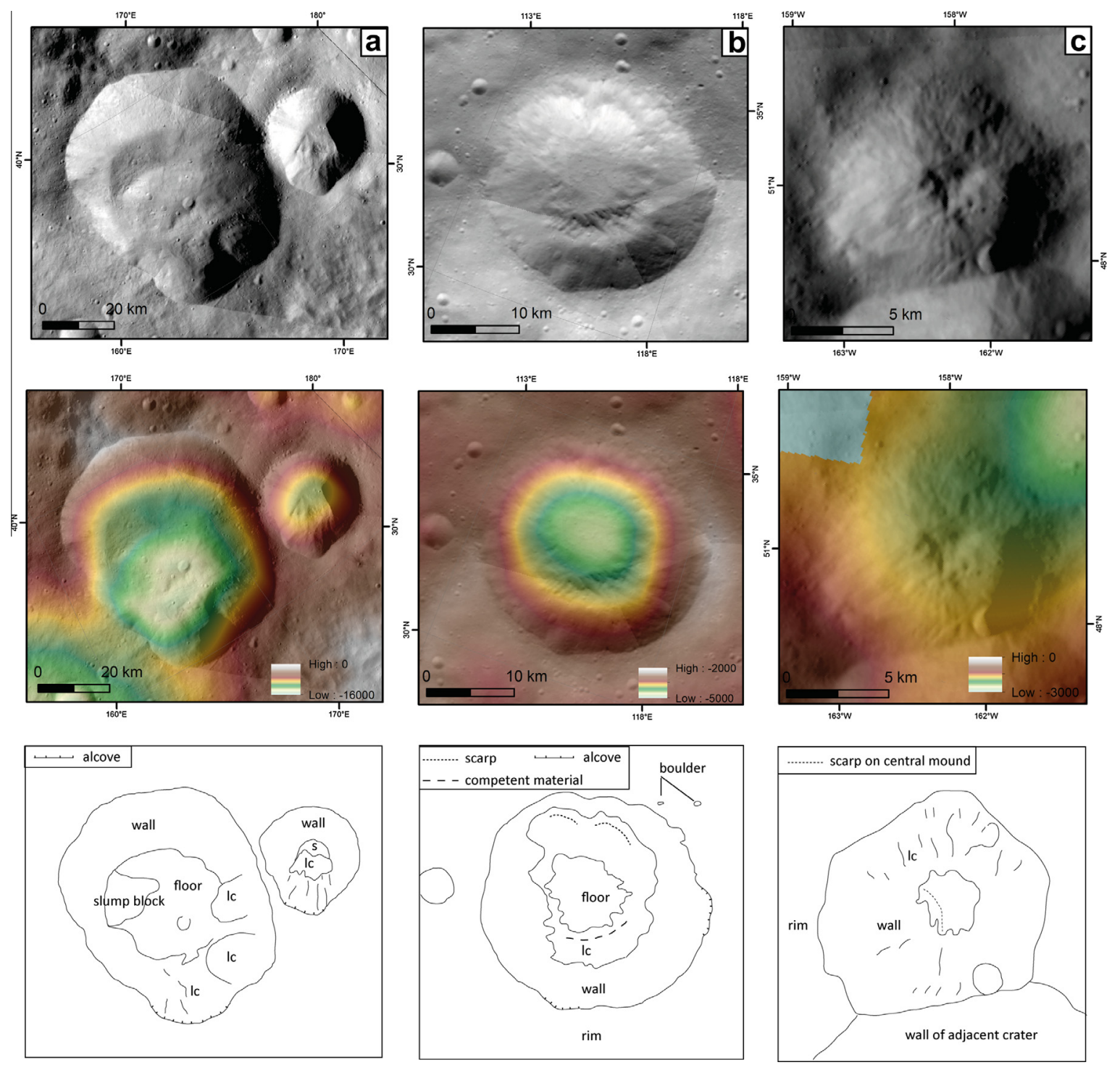

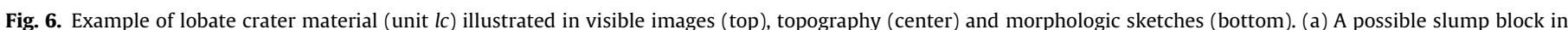

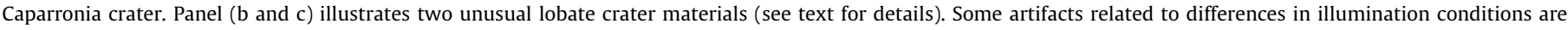
present in the mosaic.

is located in which lobate crater material is not found in the crater center, but at the bottom of the rim, forming a sub-circular feature (Fig. 6b). Part of the sub-circular feature forms a positive relief, suggesting competent material. The floor is free from lobate material and is flat (unit $s$ ). At the rim are observed possible elongated boulders up to $\sim 700 \mathrm{~m}$ in size. The asymmetric crater itself was formed on the rim of the Caesonia basin. At $50^{\circ} \mathrm{N} / 200^{\circ} \mathrm{E}$ (Fig. 6c) lobate crater material forms a central mound, similar to the floor of Licinia crater. Although the spatial resolution is limited, the central mound seems to be incised by a scarp, which would indicate that the mound is formed by competent material. Despite the fact that there are numerous craters of similar sizes and relative ages within the map area, we only observe these unusual morphologies at the few locations mentioned above.

Interpretation: This unit formed by accumulated material transported by gravitational downslope mass movement. The time of emplacement could be during the modification stage (e.g., Melosh, 1989), as well as long after the crater formation. The processes triggering the downslope movement could be related to local craters forming near the crater rim (e.g., Bellicia crater), or may be regional/global seismic shaking due to large impacts elsewhere on Vesta. The juxtaposition of several occurrences of unit $l c$ with clear contacts indicates several episodes of downslope movement. Both units $l c$ presented in Fig. $6 \mathrm{~b}$ and c show evidence for competent material, such as the presence of scarps. This is unusual for mass wasting deposits, which are often formed by unconsolidated and loose materials (e.g., Summerfield, 1991). Thus, for the craters in Fig. $6 \mathrm{~b}$ and $\mathrm{c}$ the unit might not represent typical mass wasting accumulations. These craters could correspond to concentric mound craters observed on the Moon and on Phobos (e.g., Thomas et al., 2000). On these latter bodies, these craters have been interpreted to indicate the presence of a sharp strength discontinuity between loose regolith and a coherent substrate (e.g., Quaide and Oberbeck, 1968). The coherent material potentially present at the location of Fig. $6 \mathrm{~b}$ could be derived from the excavation of the Caesonia basin. Alternatively, for the example in Fig. 6c, the central mound might be the result of fast-moving debris streams reaching the crater floor during the collapse phase, and piling up in low mounds (e.g., Melosh, 1989). One would, however, expect this material to be unconsolidated. The fact that these are the only 
examples of atypical features and the lack of a discernable relation with crater diameter or location prevents an unambiguous interpretation for their formation.

$d c$ - dark crater material: This unit is characterized by low albedo relative to regional values. It covers $0.7 \%$ of the map area. Generally, the dark-toned areas have a normal visual albedo lower than 0.2 . The unit is found in various geological contexts, usually associated with crater materials and tilted areas, and on smooth surfaces without topographic relief.

The most extensive occurrences (tens of kilometers) of the unit are at fresh crater rims, with a radial distribution starting at the rim crest. The boundary with adjacent material is gradational over few kilometers. Thus, the lowest albedo areas are usually of small extent and are located within more diffuse low albedo regions. Other occurrences of the unit are small-scale features on crater walls. Fig. 7a shows the occurrences of the unit at the relatively fresh crater Licinia. Striations on the crater wall display a teardrop-like shape with well-defined boundaries in relation to adjacent, relatively bright wall material. The figure also shows a possible accumulation of dark-toned material at the base of the slope, which occurs as small patches with well-defined boundaries. Note that the slope is as great as $40^{\circ}$ near the rim crest. Similar features are observed at Arruntia crater (Fig. 8a, shadowed area). Fig. $7 \mathrm{~b}$ shows albedo striations along the wall with slopes of $\sim 30-35^{\circ}$, starting near the crater rim and often ending midway down the crater wall, aligned with the downslope direction. The boundaries of the striations are often gradational, over a few hundred meters. Adjacent striations of bright material (unit $b c$ ) may be present. On one occasion, the source of the dark material is a small $(\sim 1 \mathrm{~km})$ crater on the rim crest of a larger crater. The crater wall in Fig. 7a also shows a dark band parallel to the wall crest (i.e., perpendicular to the downslope direction). Fig. 7c shows that the unit might also originate from spots at different elevation on the crater wall. The source spots are unresolved at LAMO resolution.

Unit $d c$ also forms halos around very small ( $<1 \mathrm{~km})$ craters (e.g., near Caparronia crater).

Interpretation: The major reason for the low albedo is the presence of material that is compositionally different than the surroundings (Reddy et al., 2012b; McCord et al., 2012). A second-order effect that could contribute to the low albedo is a relatively coarse grain size in the dark material (e.g., Cloutis et al., 2013), or the effects of space weathering (e.g., Pieters et al., 2012).

The occurrence of unit $d c$ depends on the mechanism by which the material has been exposed at the surface. For the extensive unit $d c$ near fresh craters, the young impacts themselves have probably exposed or delivered the material. For the small-scale occurrences of unit $d c$ (i.e., on crater walls) we suggest that downslope movement (i.e., dry debris flow) is important for exposing the material. Overall, in Fig. 7a and b, the morphologies are similar to what has been observed on Eros (e.g., Mantz et al., 2004; Robinson et al., 2002; Thomas et al., 2002). On Eros, the presence of different albedo regions on the same slope indicates that downslope movement is low momentum, and the presence of sharp albedo boundary suggests that the movement may be halted due to friction (Mantz et al., 2004). For our study area we have made very similar observations of bright and dark material, thus suggesting that the albedo differences on Vesta are formed in a similar fashion to those on Eros. Rapid processes might also occur, as suggested by the teardrop-like feature in Fig. 7a, reminiscent of a fine-grained
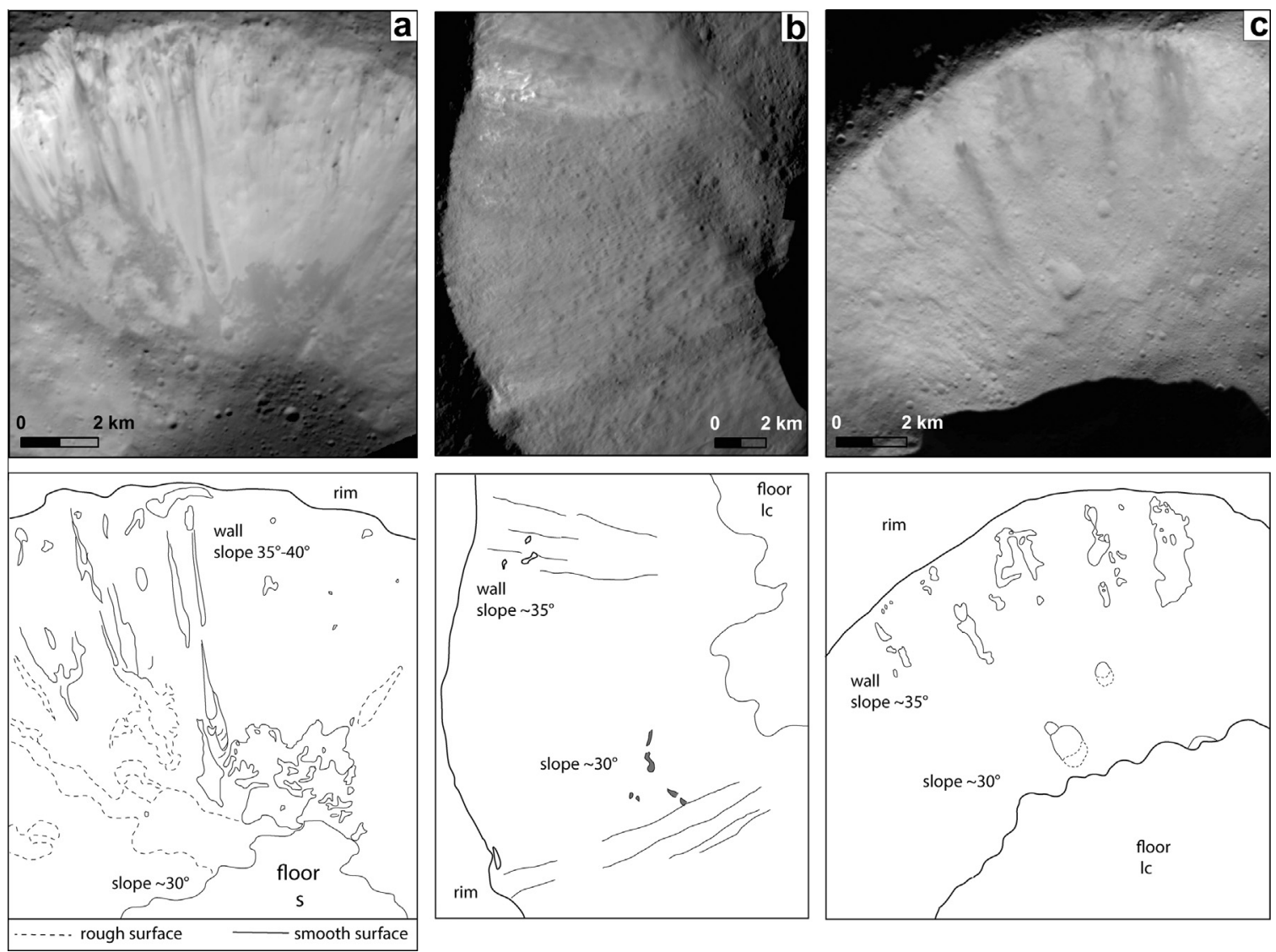

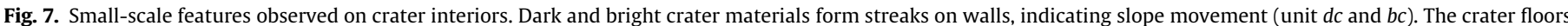

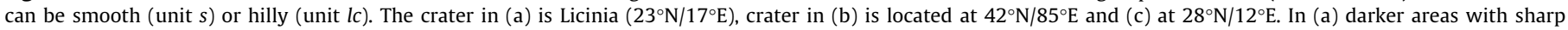
boundaries are sketched. In ( $\mathrm{b}$ and $\mathrm{c}$ ) darker areas have diffuse boundaries. 

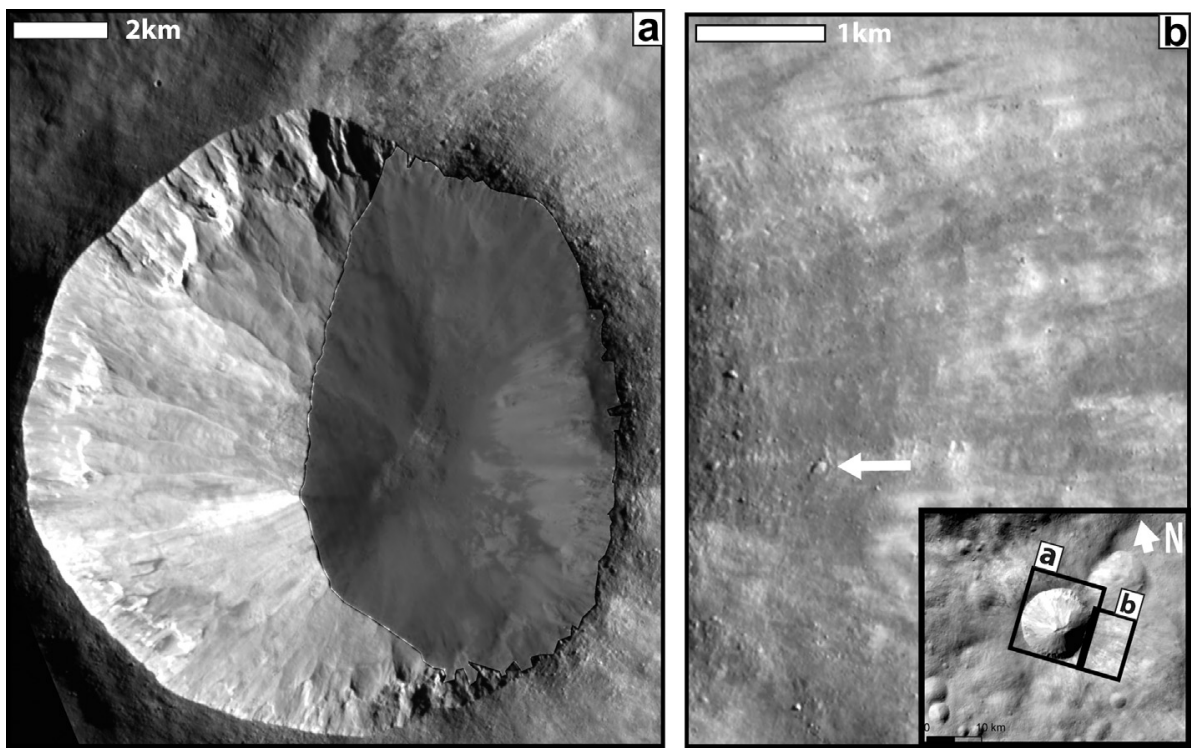

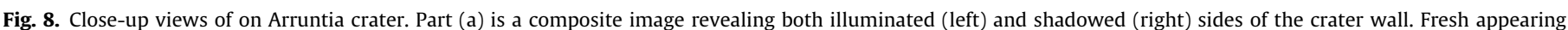

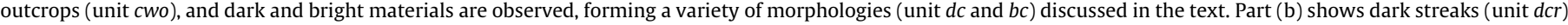
and bright crater ejecta. Arrow points to a boulder $\sim 400 \mathrm{~m}$ in size, partly covered by the ejecta. Inset in (b) shows the locations of the close-ups.

avalanche. Note also that albedo streaks might not only result from compositional variations, but could be due to removal of a thin layer of fine-grained material (e.g., Schorghofer and King, 2011; Kumar et al., 2013).

Several mechanisms have been proposed to trigger downslope movement, including impact processes and seismic shaking or electrostatic and thermal effects (e.g., Mantz et al., 2004). Due to the lack of fresh craters, seismic shaking was less favored on Eros (Mantz et al., 2004). However, this process is plausible on Vesta, since numerous fresh craters are observed in the study area (e.g., Arruntia crater).

Several scenarios could explain the appearance of unit $d c$ in Fig. 7c. The unit $d c$ could be homogeneously distributed on the crater wall, but is exposed by discrete small impacts. Alternatively, the dark material could have been previously distributed as striations as in Fig. 7b, and was subsequently buried by brighter material or was gardened by very small impacts. Subsequent small craters would have excavated the striation material and created the observed discrete patches.

The dark material on Vesta might have an endogenous (i.e., impact melt and/or basaltic material) or exogenous (carbonaceous chondrite material delivered by low velocity meteoroids) source. The exogenous origin is preferred on the basis of the global distribution of the dark unit and on impact modeling (Reddy et al., 2012 b). A relationship between this unit and $\mathrm{OH}$-bearing material has been found (De Sanctis et al., 2012b). The nature of the $\mathrm{OH}-$ bearing material, however, is still unclear (i.e., whether related to basaltic material or to carbonaceous chondrites) (De Sanctis et al., 2012b).

Like any other surface material on Vesta, unit $d c$ is subject to regolith gardening and is expected to brighten with time due to contamination by vertical and lateral mixing with brighter material (McCord et al., 2012; Pieters et al., 2012). Thus, we interpret unit $d c$ to be of relatively young age.

$d c r$ - dark crater ray material: Unit dcr shares the characteristics of unit $d c$, but exhibits an additional rayed pattern. It covers $0.1 \%$ of the map area. The rays usually extend around the source crater for 2-3 crater radii. The rays might be straight and very narrow $(\sim 200 \mathrm{~m})$ or show a discontinuous distribution (e.g., Arruntia crater, Fig. 8b).
Interpretation: The same interpretations on the source of the dark material of unit $d c$ apply to unit $d c r$.

$b c$ - bright crater material: Unit bc consists of smooth areas with high albedo relative to regional values. It covers less than $0.1 \%$ of the map area. The normal visual albedo is higher than 0.4 . The unit occurs in several geologic contexts. In some places the unit is found at crater rims in association with unit hcm (e.g., Pomponia crater), or forms halos around very small $(<1 \mathrm{~km})$ craters. The unit forms striations on the walls of fresh craters. Usually the striations are shorter than those of unit $d c$ and have a diffuse boundary. The source regions of the striations cannot be spatially resolved; often, however, they are found close to crater wall outcrops (unit cwo). Often striations start at constant heights within the crater walls, or are aligned sub-parallel to the rim crests.

Interpretation: The high albedo of unit $b c$ is interpreted as fresh exposures of unweathered materials (e.g., Reddy et al., 2012a; McCord et al., 2012; Pieters et al., 2012). The surface of Vesta is affected by space weathering (e.g., Pieters et al., 2012) and the main effect is the lowering of the albedo (i.e., darkening). Thus, the $b c$ material could represent pristine, crystalline material. The unweathered material can be exposed in craters and form ejecta blankets (halos), or exposed by downslope movement, or as crater wall outcrops. Similar to the exposure of unit $d c$, downslope movement can be triggered by impacts and seismic shaking.

$b c r$ - bright crater ray material: Unit $b c r$ is similar to unit $b c$, but can be distinguished by a radial rayed pattern around the source crater. Unit $b c r$ covers $0.3 \%$ of the map area. At Arruntia crater (Fig. 8), rays of unit bcr extend for up to 10 crater radii.

Interpretation: The ray materials might be unweathered ejecta from the source crater and/or dislodged or exposed local material (e.g., Oberbeck, 1971; Hawke et al., 2004; Melosh, 1989).

$d l$ - dark lobate material: Unit $d l$ is characterized by dark lobate material ( $\sim 1 \mathrm{~km}$ wide, $\sim 5-10 \mathrm{~km}$ long) with clear onlapping contacts onto adjacent surface units. It covers $0.1 \%$ of the map area. The material extends from crater rims toward topographic lows, has a smooth appearance, and displays a flow-like morphology (Fig. 9). The unit is found on the fresh crater ejecta (unit $d c / u c$ ) of Minucia and Marcia craters.

Interpretation: The morphology of the unit, its association with Minucia and Marcia dark-toned ejecta materials, and its 
similarities with lunar impact melt flow features (e.g., Schultz, 1976; Hawke and Head, 1977; Bray et al., 2010; Osinski et al., 2011; Ashley et al., 2012) suggest an impact melt origin of the unit (Williams et al., in press). Ejecta debris-flow deposits constitute an alternative interpretation. Unfortunately, unambiguous morphological observations are only possible with LAMO data. The lack of LAMO coverage for the northern areas prevents any clear identification of this unit near other fresh craters at high northern latitudes.

$s$ - smooth material: The material of unit $s$ fills and usually flattens crater floors. It covers less than $0.1 \%$ of the map area. The surfaces of this unit have a smooth appearance at HAMO-2 resolution. The occurrences of this unit between Marcia and Caparronia craters are within unit $u c / h c m$ of these large craters (Fig. 2). In one location (close to Domitia crater) pits are found within the smooth area. In other locations (Fig. 7), the unit shows a very smooth surface and is dark relative to its surroundings. At Licinia crater (Fig. 10), pits might also be present, but the available spatial resolution of the images hinders their unambiguous identification.

Interpretation: This unit could have a variety of origins. Between Marcia and Caparronia, the presence of ubiquitous ejecta materials suggests infilling of preexisting craters by ejecta material from the two large craters. At Licinia crater the material is probably related to the impact itself, since Licinia is the only young crater in the region. Similar deposits are observed on the ejecta blanket outside the Licinia crater (Fig. 10, close up 3). Mass wasting accumulations of coarse debris can be excluded since they are found elsewhere in the crater with a different morphology (Fig. 10). However, smooth-surfaced ponds of fine debris are observed on the Moon with a similar appearance (e.g., Kumar et al., 2013). The occurrences of unit $s$ in Licinia crater shows morphologies that are also very similar to impact melt deposits on the lunar surface (e.g., Plescia and Cintala, 2012; Schultz, 1976). While the production of melt during impact is expected to be limited on small bodies (e.g., Keil et al., 1997), recent modeling and observation suggest the presence of impact melt on Vesta (Williams et al., in press; Le Corre et al., 2013) and support the interpretation of impact melt deposits in and around Licinia crater. For the smooth deposits on Eros, electrostatic levitation with subsequent transport and redistribution of the finer fraction of the regolith into ponds has been proposed (Robinson et al., 2001). The origin of smooth deposits on Vesta requires further investigation.

Pits found within smooth areas are an unexpected morphology on Vesta, and preliminary analysis suggests an origin related to devolatilization (Denevi et al., 2012a,b). These pits occur on a smooth surface when viewed at HAMO-2 resolution. Where LAMO resolution is available, however, the surface appears rough. Moreover, in several locations the unambiguous identification of pitted terrains is not possible due to the lack of LAMO images. Pitted terrains are more extensively found in southern areas, e.g., quadrangle Av-8 (Williams et al., this issue-b).

cwo - crater wall outcrop: Unit cwo consists of more competent material that is exposed on the walls of fresh craters (unit $u c / h c m$ ), such as rock spurs. It covers less than $0.1 \%$ of the map area. Several occurrences of the unit are observed at a given crater at approximately the same height on the wall (e.g., Bellicia crater, Mamilia crater, Arruntia crater, Fig. 8a). In other craters the unit is visible in only one quadrant of the wall and at different heights (e.g.,
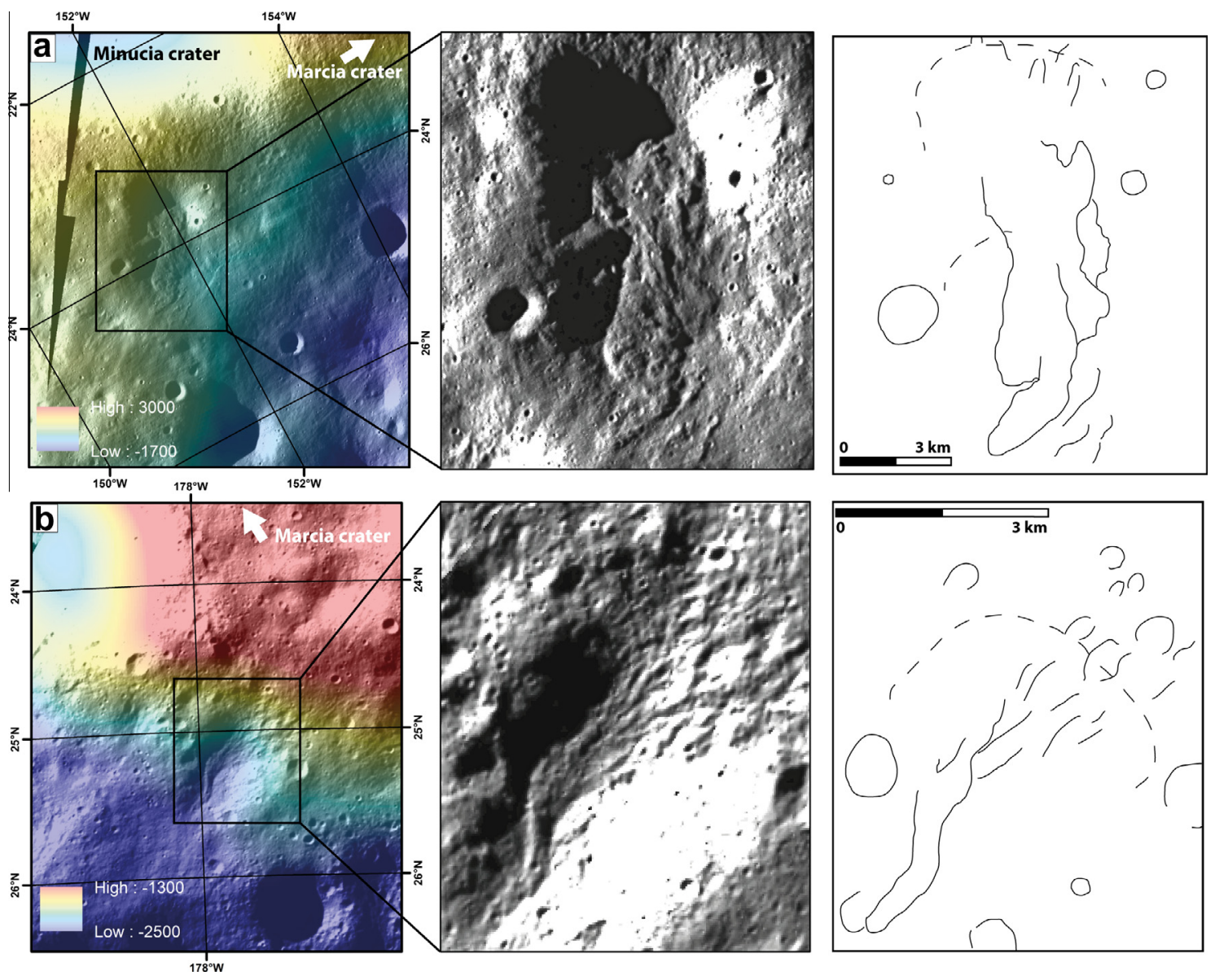

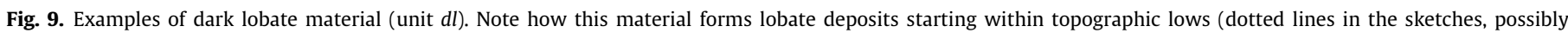
craters) and extending downslope, away from Marcia crater. 

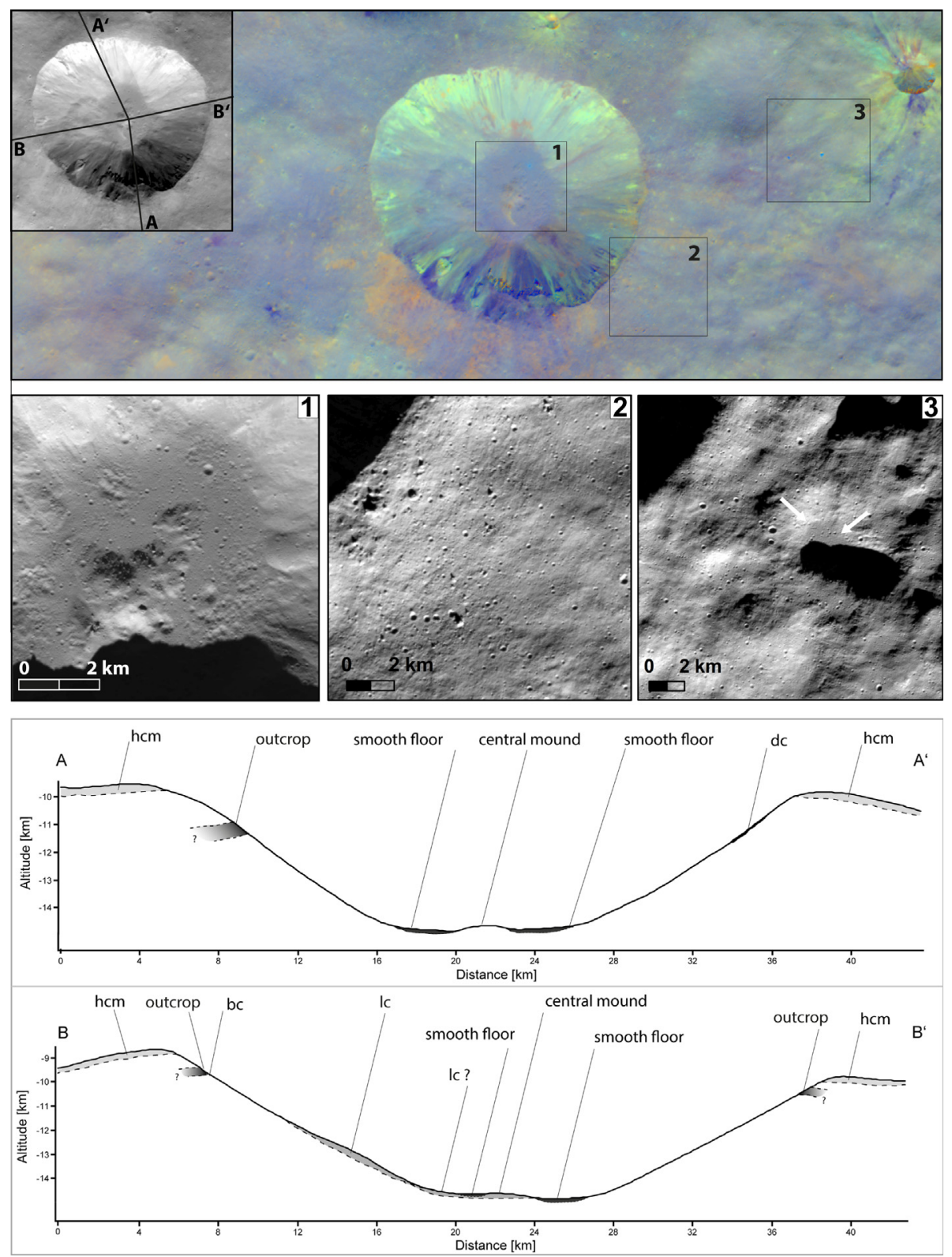

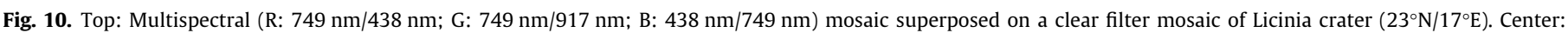

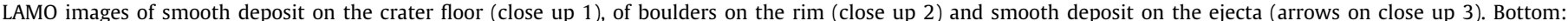

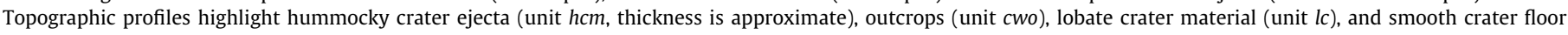
(unit s).

Licinia crater). Compared with adjacent surfaces, a higher albedo is observed for the unit.

Interpretation: The occurrences of this unit suggest the exposure of competent material, found below layers of material that is probably unconsolidated. One could speculate that the material forms a continuous layer sub-parallel to the regional topography, consisting of either material overturned by the impact or an unmodified preexisting layer. Observations at some craters suggest, however, the presence of discontinuous competent zones at varying depths. The material could represent consolidated impact derived-breccia or blocks of an original igneous crust.

\subsection{Topography}

The most widespread area of unit $c h\left(\right.$ at $40^{\circ} \mathrm{E} / 70^{\circ} \mathrm{N}$ ) is characterized by a relatively high elevation, with an average altitude of $0 \mathrm{~km}$ relative to the datum. The approximate location of this plateau is bound by the craters Torquata, Bellicia, Arruntia and Poponia. The boundary of this area is controlled by large-scale troughs and large degraded basins. In places, degraded craters create circular topographic depressions ("Albana-Mamilia" basin, 98-102 km in diameter). Within the plateau, an area of higher topography ( $\sim 5 \mathrm{~km}$ above the datum) is centered at $47^{\circ} \mathrm{N} / 62^{\circ} \mathrm{E}$, between the craters Bellicia, Albana and Arruntia. The boundary of the elevated area is partly controlled by degraded craters.

The topography of unit Sft is controlled by troughs and ridges, creating elevation differences of up to $6 \mathrm{~km}$, and slopes of $\sim 30^{\circ}$. Topographic highs within unit $S f c$ are related to the rims of large and fresh craters, up to $\sim+9 \mathrm{~km}$ in elevation.

Large topographic lows in the map area are due to three degraded basins that cross units ch, Sft and Sfc (Figs. 1a, c and 2). These basins are recognized as topographic lows with a 
sub-circular shape. Their walls have a muted morphology with slopes of $\sim 20^{\circ}$ over $15-20 \mathrm{~km}$. The diameters range from 95 to $105 \mathrm{~km}$ for the Caesonia basin, $180-210 \mathrm{~km}$ for the Varronilla basin and $\sim 200 \mathrm{~km}$ for the Postumia basin. The topography within these basins is heterogeneous and controlled by smaller degraded craters. The elevation within the basins can be as low as $-16 \mathrm{~km}$ (i.e., in the Caesonia basin). Such low elevations are only found in two other locations on Vesta: within the Rheasilvia basin and within the Feralia Planitia basin.

In Licinia crater we observed particular topographic features, which are shown using two cross-sections in Fig. 10. Both profiles schematically illustrate the ejecta blanket, which is at least several tens of meters thick. Profile A-A' shows a $\sim 700 \mathrm{~m}$ thick outcrop, located $\sim 1560 \mathrm{~m}$ below the crater rim. Other outcrops visible in the $\mathrm{B}-\mathrm{B}^{\prime}$ profile are different in thickness $(\sim 400 \mathrm{~m})$, and are located at shallower depths ( $550 \mathrm{~m}$ below the crater rim). The consolidated nature of such outcrops is confirmed by the slopes reaching $>40^{\circ}$, above the angle of repose (Jaumann et al., 2012). Streaks and accumulation of dark material occur on slopes of $>35^{\circ}$. The lobate crater materials have slopes of $\sim 30^{\circ}$. The floor of Licinia crater is characterized by a central mound that reaches $150 \mathrm{~m}$ above the smooth surroundings. The smooth floor has a slope of $1-4^{\circ}$. In profile $\mathrm{B}-\mathrm{B}^{\prime}$ it can be recognized that the central mound is possibly a continuation of mass wasting deposits starting at mid-wall and extending to the bottom of the wall and the floor. Parts of the mass-wasting deposits are covered by the dark-toned smooth unit. The latter unit could correspond to an impact melt sheet. This configuration of debris slumping and possible melt rock is consistent with typical simple craters on the Moon (e.g., Melosh, 1989). Thus, it is less likely that the central mound represents a central peak.

Several $\sim 10 \mathrm{~km}$ large craters near Caparronia and Marcia craters display a filled floor (unit s). Depth-to-diameter ratios for fresh simple craters on Vesta are estimated at $\sim 0.18$ (Jaumann et al., 2012). Applying this ratio, the thickness of the infilling varies from 0.2 to $\sim 1.6 \mathrm{~km}$, being larger for craters close to Marcia.

\subsection{Absolute model age determinations}

In the map area, several large fresh craters display slightly different morphologies, suggesting different formation ages. To further investigate the different ages, we have performed crater size-frequency distribution measurements (CSFD) for craters Arruntia, Licinia, Scantia, Bellicia, Floronia, Mamilia, Caparronia, Torquata, and Pomponia. Marcia crater was also studied for comparison since globally it represents a major young impact (Jaumann et al., 2012; Williams et al., this issue-b). The crater counting areas were selected within units $u c$ or hcm. Fig. 11 displays the counting areas and the CSFD measurements performed on HAMO-2 and LAMO images. The CSFD of each crater was fitted with an isochron over the widest possible crater diameter range. For the fit, the largest diameters were disregarded since they represent underlying and preexisting craters buried by the impact ejecta of the investigated fresh craters. At the time of writing, debate concerning the surface ages of Vesta is ongoing. In particular, those ages depend on the underlying models, i.e., the production function (PF) and the chronology function (CF). While Schmedemann et al. (in preparation) favor a lunar-like PF and CF, O'Brien (in preparation)/Marchi et al. (2012) favor a chronology based on Main Belt dynamics. Table 1 summarizes the age derivations obtained with the approaches of Schmedemann et al. (in preparation) and of O'Brien (in preparation)/Marchi et al. (2012).

When using the PF of Marchi et al. (2012) we found that, for most of the investigated craters, the slope of our CSFDs is steeper than the proposed production function. This difference prevented obtaining reliable fits between our CSFDs and the isochrons. Depending on the range of crater diameters used for the fit, the O'Brien (in preparation)/Marchi et al. (2012) AMA varied by more than 100 Ma. Thus, we derived an AMA only for a few of the study craters for which the counts could be reasonably well fitted with the production function of Marchi et al. (2012) (see Table 1).

The CSFDs for Caparronia and Floronia crater did not provide a reliable model age, using neither the functions of Schmedemann et al. (in preparation), nor those of O'Brien/Marchi et al. (2012). This is due to the presence of fields of secondary craters (for Caparronia) and of surface disturbance (e.g., furrows) near Floronia (Fig. 2). Nevertheless, some constraints on the relative age of Caparronia can be inferred from the superposition of ejecta material from Marcia and the crisp appearance of Caparronia's rim crest. Thus, Caparronia crater is older than Marcia ( $100 \mathrm{Ma}$ ), but younger than Bellicia ( 630 Ma).

From our stratigraphic observations it can be inferred that three named degraded craters, Albana, Domitia and Eutropia have
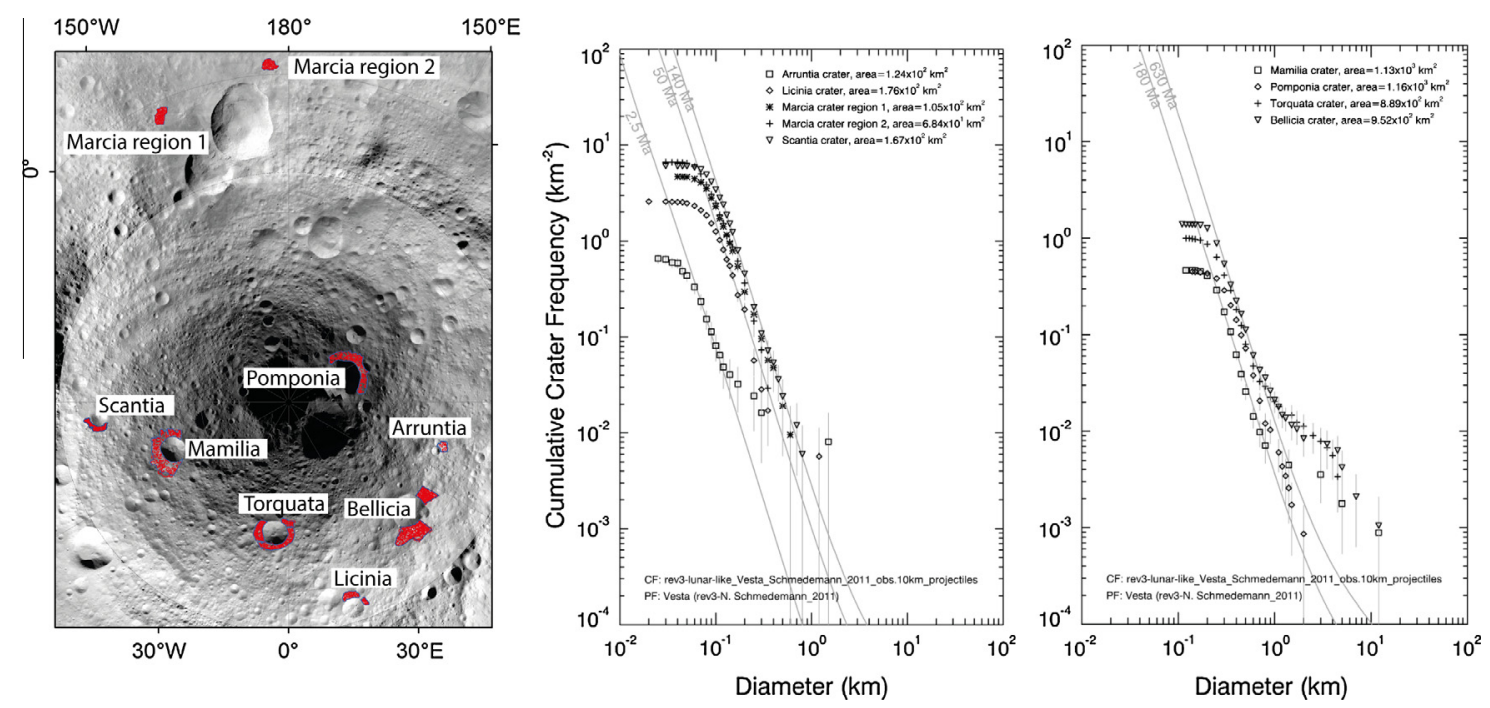

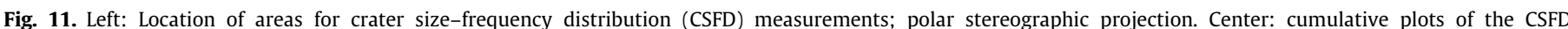

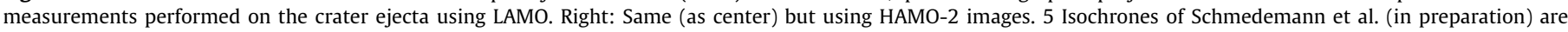
plotted for reference. 
formed before unit $u c$ of Bellicia, Torquata and Pomponia, which are the oldest dated craters. This is because the degraded craters lack any evidence of ejecta blankets and their rim crests are smoothed. Albana crater probably formed later than Domitia and Eutropia, because its rim crest is sharper than the other two craters. Domitia crater occurs on unit $S f t$; because no trough or ridge is present on the crater interior (Figs. $1 \mathrm{~b}$ and 2), it likely postdates the formation of unit Sft. Tentatively, it can be assumed that craters of similar morphology (e.g., Eutropia) also formed after unit Sft.

To verify whether the three major geologic units, ch, Sft and Sfc, formed at distinct periods of time, we performed CSFD measurements. The count area for unit Sft is centered at $105^{\circ} \mathrm{E} / 30^{\circ} \mathrm{N}$, and for unit $S f c$ at $330^{\circ} \mathrm{E} / 30^{\circ} \mathrm{N}$. The count area for unit $\mathrm{ch}$ is located within $335-35^{\circ} \mathrm{E}$ and $20-45^{\circ} \mathrm{N}$. In addition, in order to relate these units with the cratered highland unit mapped in the equatorial regions (unit ch: Yingst et al., 2014), we have performed CSFD measurements in two different locations: in Vestalia Terra and in a region centered at $20^{\circ} \mathrm{E} / 10^{\circ} \mathrm{N}$. All CSFD measurements were performed on the HAMO-1 mosaic, which has satisfactory illumination conditions and spatial resolutions for all units.

CSFD measurements for the above units were performed in the diameter range of $\sim 3 \mathrm{~km}$ to $20 \mathrm{~km}$. The upper limit is defined by the areal extent of the units. The lower limit is defined by the spatial resolution of the mosaic. The CSFD measurements between $\sim 8 \mathrm{~km}$ and $\sim 11 \mathrm{~km}$ for areas formed before the Rheasilvia impact are offset from the Vesta's isochrons (Marchi et al., 2012; Schmedemann et al., in preparation). The absolute model ages derived from CSFD in this diameter range are thus uncertain. The CSFDs of unit $S f t$, unit $S f c$, unit $c h$, and the CSFD for the equatorial highland at two locations did not revealed clear differences. Thus, despite the fact that no unambiguous absolute model age can be derived with these measurements, they still indicate a very similar crater density between the five units. The crater density in this diameter range is the highest found on Vesta.

\section{Discussion}

Here we discuss a plausible temporal sequence of events that has led to the formation of the mapped materials from the earliest to the youngest. Fig. 12 shows the proposed stratigraphy based on this discussion.

The very earliest events are not recorded by the surface morphology because of subsequent heavy modification by impacts. Large-scale topographic structures, however, are less subject to modification by impacts and could still preserve the record of some early events. The relatively high elevation of unit $c h$ (centered at $40^{\circ} \mathrm{E} / 70^{\circ} \mathrm{N}$ ) is rarely found outside the northern hemisphere. Similar elevations are found north of the Divalia Fossae system at longitudes of $\sim 10^{\circ} \mathrm{E}, \sim 160^{\circ} \mathrm{E}$ and at around $250^{\circ} \mathrm{E}$. Thus, unit $c h$ located at $40^{\circ} \mathrm{E} / 70^{\circ} \mathrm{N}$ could be considered as one of the few areas having a higher topography, lower only than Vestalia Terra. Within the plateau of unit $c h$, the high elevation of the area centered at $47^{\circ} \mathrm{N} / 62^{\circ} \mathrm{E}$ (between Bellicia, Albana and Arruntia craters) could be a remnant of the ejecta of the Varronilla basin, and its current shape could be the result of subsequent crater excavation. Similar high-standing topography in unit $c h$ is only found in one additional location around the Varronilla basin, near the Torquata crater. In this second location, the topography is partly the result of the fresh crater Torquata and of a ridge of unit $S f c$. The crater Torquata is also located close to the Veneneia antipode $\left(65^{\circ} \mathrm{N} / 350^{\circ} \mathrm{E}\right)$, where antipodal uplift could be expected (e.g., Bowling et al., 2013; Blewett et al., submitted for publication). The ejecta of the Varronilla basin would need to be unevenly distributed to create an elevated area only near $47^{\circ} \mathrm{N} / 62^{\circ} \mathrm{E}$ and near Torquata. Alternatively, an uneven excavation by subsequent impacts would be required. The topographic high could also be due to antipodal uplift, as discussed in Blewett et al. (2014), or be a remnant of a large-scale ridge. The elevated area might also be, in part, the result of an event predating the basins. Outside the northern hemisphere, similar or higher altitudes are only found in Vestalia Terra. As mentioned earlier, Vestalia Terra could still preserve some pristine geologic characteristics (i.e., gravitational anomalies, magmatic intrusion at Brumalia Tholus) (Raymond et al., 2013; Buczkowski et al., 2013). Similarly, the northern cratered highland (unit $c h$ ) could also possibly keep the record of some early-formed geologic features.

The oldest impact structures of the hemisphere are three basins with diameters of 100-200 km and highly subdued morphologies. The Varronilla basin and the Caesonia basin partly excavated into the elevated topography of unit $c h$ centered at $40^{\circ} \mathrm{E} / 70^{\circ} \mathrm{N}$. Thus, these two impacts postdate the formation of unit $c h$.

A third large ruined basin (Postumia basin) is the most extensively modified basin. Its floor is characterized by the well-defined troughs and ridges of the Saturnalia Fossae trough material (unit $S f t$ ), and a topographically higher plateau replaces its northern rim. Unit Sft formed as a consequence of the Veneneia impact (Jaumann et al., 2012; Buczkowski et al., 2012), which is one of the large ancient impacts on Vesta (Schmedemann et al., in preparation; Marchi et al., 2012). Other ridges and troughs found in the Varronilla and the Caesonia basins could be related (i.e., formed/ reactivated) to smaller basins elsewhere on Vesta.

We have not found any clear differences in CSFDs between unit $S f t$, unit $S f c$ and unit $c h$. This suggests that the units formed in the ancient past and have undergone intense subsequent bombardment. Units $S f t, S f c$ and $c h$ share CSFD characteristics with the cratered highland in the equatorial region of Vesta (e.g., Vestalia Terra), suggesting that the units represent the oldest terrain on Vesta.

After the Veneneia impact, the southern hemisphere was heavily affected by the Rheasilvia impact. Impact modeling suggests that the Rheasilvia ejecta were globally distributed, reaching also the northern hemisphere (e.g., Jutzi et al., 2013b). Dawn observations show that mantling by Rheasilvia impact debris is limited to within $100 \mathrm{~km}$ from the rim (e.g., Schenk et al., 2012) and that the debris morphology changes from flow-like features close to the rim to ripples away from the rim (Otto et al., 2013). In the northern hemisphere, we did not find any evidence for an ejecta layer that could be unambiguously linked to Rheasilvia. This is consistent with the global-scale geologic map (Yingst et al., 2014). The small-scale lineations are possible evidence of the effects of Rheasilvia. The observed broad N-S trend of some lineations and their appearance as incised grooves suggests that material ejected from the Rheasilvia has impacted in the northern hemisphere. Possible Rheasilvia antipodal effects are discussed further by Blewett et al. (2014).

At a global scale, all geologic units that (on the basis of crosscutting relationships) are inferred to be older than the Rheasilvia impact show a deviation from the isochron in the diameter range $\sim 8-11 \mathrm{~km}$ (Schmedemann et al., in preparation; Marchi et al., 2012). Our measurements of CSFD on unit ch, Sft, and Sfc confirm these observations. This deviation might be the result of pre-Rheasilvia impacts or caused by secondary cratering from the Rheasilvia impact.

Post-Rheasilvia events include the formation of impact craters smaller than $\sim 60 \mathrm{~km}$. Overall, the crater retention ages for the ejecta blankets of these craters (see Section 4.5) are consistent with the morphologies of the craters presented in the geologic map. The oldest craters, such as Bellicia, Torquata, Pomponia display the least-sharp rim crests, and floors that are covered by mass wasting deposits. Caparronia may have formed after these craters because it has a crisper rim. Even younger craters Scantia and Mamilia exhibit sharper rim crests and discontinuous ejecta units. Slightly 
Table 1

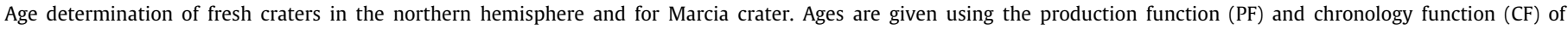
Schmedemann et al. (in preparation) and O'Brien et al. (in preparation)/Marchi et al. (2012).

\begin{tabular}{|c|c|c|c|c|c|c|c|c|c|c|c|}
\hline \multirow[t]{2}{*}{ Crater name } & \multirow{2}{*}{$\begin{array}{l}\text { Count } \\
\text { area } \\
\left(\mathrm{km}^{2}\right)\end{array}$} & \multicolumn{5}{|c|}{ PF and CF of Schmedemann et al. (in preparation) } & \multicolumn{5}{|c|}{ PF of Marchi et al. (2012) and CF of O'Brian et al. (in preparation) } \\
\hline & & $N_{\text {cum }}(D \geqslant 1 \mathrm{~km})$ & $\begin{array}{l}\text { Error on } \\
N_{\text {cum }}(D \geqslant 1 \mathrm{~km})\end{array}$ & $\begin{array}{l}\text { No. } \\
\text { crater } \\
\text { fitted }\end{array}$ & $\begin{array}{l}\text { AMA } \\
\text { (Ma) }\end{array}$ & $\begin{array}{l}\text { Error on } \\
\text { AMA } \\
\text { (Ma) }\end{array}$ & $N_{\text {cum }}(D \geqslant 1 \mathrm{~km})$ & $\begin{array}{l}\text { Error on } \\
N_{\text {cum }}(D \geqslant 1 \mathrm{~km})\end{array}$ & $\begin{array}{l}\text { No. } \\
\text { crater } \\
\text { fitted }\end{array}$ & $\begin{array}{l}\text { AMA } \\
\text { (Ma) }\end{array}$ & $\begin{array}{l}\text { Error on } \\
\text { AMA } \\
\text { (Ma) }\end{array}$ \\
\hline Arruntia & 123.6 & $5.07 \mathrm{E}-05$ & $7.84 \mathrm{E}-06$ & 37 & 2.5 & 0.4 & $2.92 \mathrm{E}-04$ & $4.52 \mathrm{E}-05$ & 37 & 14.6 & 2.3 \\
\hline Licinia & 175.8 & $1.01 \mathrm{E}-03$ & $9.40 \mathrm{E}-05$ & 112 & 49.5 & 4.6 & Fit uncertain ${ }^{\mathrm{a}}$ & & & & \\
\hline Marcia region 1 & 104.7 & $1.94 \mathrm{E}-03$ & $2.11 \mathrm{E}-04$ & 83 & 95.2 & 10.0 & $5.33 \mathrm{E}-03$ & $9.49 \mathrm{E}-04$ & 30 & 266.2 & 47.2 \\
\hline Marcia region 2 & 68.4 & $2.07 \mathrm{E}-03$ & $2.66 \mathrm{E}-04$ & 59 & 101.0 & 13.0 & Fit uncertain ${ }^{\mathrm{a}}$ & & & & \\
\hline Scantia & 166.8 & $2.83 \mathrm{E}-03$ & $1.95 \mathrm{E}-04$ & 206 & 139.0 & 9.6 & Fit uncertain ${ }^{\mathrm{a}}$ & & & & \\
\hline Mamilia & 1125.5 & $3.58 \mathrm{E}-03$ & $2.55 \mathrm{E}-04$ & 189 & 176.0 & 12.0 & Fit uncertain ${ }^{\mathrm{a}}$ & & & & \\
\hline Pomponia & 1161.7 & $7.61 \mathrm{E}-03$ & $4.91 \mathrm{E}-04$ & 235 & 373.0 & 24.0 & Fit uncertain ${ }^{\mathrm{a}}$ & & & & \\
\hline Torquata & 888.9 & $9.67 \mathrm{E}-03$ & $5.00 \mathrm{E}-04$ & 341 & 475.0 & 25.0 & Fit uncertain ${ }^{\mathrm{a}}$ & & & & \\
\hline Bellicia & 952.2 & $1.28 \mathrm{E}-02$ & $7.20 \mathrm{E}-04$ & 295 & 630.0 & 35.0 & $2.19 \mathrm{E}-02$ & $1.74 \mathrm{E}-03$ & 148 & 1083.4 & 84.8 \\
\hline
\end{tabular}

${ }^{a}$ Non-reliable fit between our CSFD and the PF of Marchi et al. (2012) (see text).

younger craters, Licinia and Marcia (see quadrangle Av-8 for Marcia), show extensive discontinuous ejecta blankets and rocky outcrops. Their crater walls can be steeper than the angle of repose and fine-grained debris flows may have occurred. Mass wasting deposits are present, but do not completely cover the crater floors. Instead, flat-floored deposits reminiscent of impact melt ponds are observed within their floor. Licinia differs from Marcia by the absence of the dark-toned unit $d c$. This difference could have several explanations. If the dark material is endogenous in origin, the two craters, with different diameters and excavation depths could have exposed different substratums. If the material is of exogeneous origin, the two impactors could have had different amounts of low-albedo carbonaceous material (e.g., Reddy et al., 2012b; McCord et al., 2012). The absence of dark-toned material at Licinia crater could also be due to the originally different thickness of the dark-toned mantle. An originally thinner mantle at Licinia crater would have disappeared more rapidly as a consequence of impact gardening. The youngest impact, Arruntia, shows dark-toned areas and rays (possibly impact melt veneer) on its rim. It has rocky outcrops and evidence for downslope movement on its walls, such as fine-grained avalanches. Arruntia has extensive bright rays that cover unit $u c$ of adjacent fresh craters. If the mechanism that has formed and destroyed the bright rays is similar to that on the Moon (e.g., Oberbeck, 1971; Hawke et al., 2004), then the ray pattern of
Arruntia would be consistent with the young age of this crater. It has been inferred that one of the effects of the space environment on the surface of Vesta is a decrease in albedo (Pieters et al., 2012). This is also consistent with the young crater retention age of Arruntia.

For Marcia crater we can compare our absolute model ages (Table 1) with previous estimates. In the study of Williams et al. (2014b), different ages of Marcia are presented with different counting areas and different production and chronology functions. Our absolute model age of Marcia can be compared only with those obtained in the same geologic unit and with the same functions. We found that our AMA of the Marcia ejecta blanket calculated with the functions of Schmedemann et al. (in preparation) is just within the error estimates of the youngest AMA presented in the work of Williams et al. (2014b) (101 $\pm 13 \mathrm{Ma}$ versus $123 \pm 9 \mathrm{Ma}$ ). We consider the counting area on the Marcia ejecta blanket to be more representative of the formation age than a counting area within the crater itself. The latter counting area, which is presented in Marchi et al. (submitted for publication) and Williams et al. (2014b), corresponds to a possible impact melt pond. Thus, the derived age of the pond could be underestimated due to target property effects as observed on the Moon and Mars (e.g., Dundas et al., 2010; Hiesinger et al., 2012; van der Bogert et al., 2010, 2013). Indeed, Marchi et al. (submitted for publication) showed

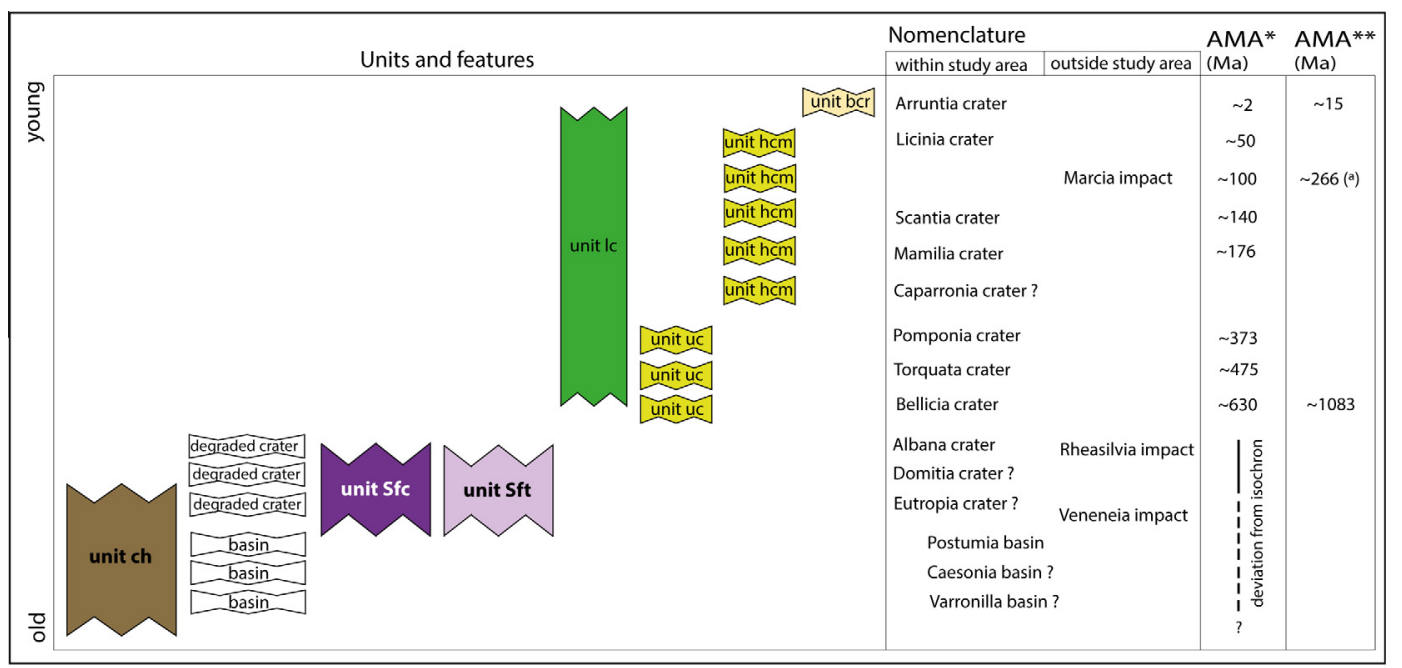

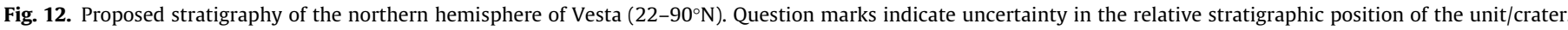

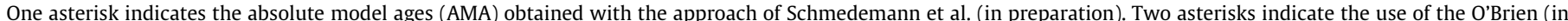

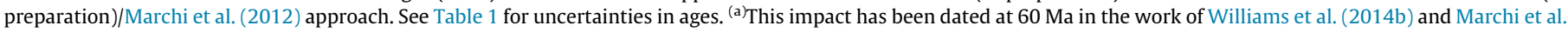
(2013). Differences between crater size-frequency measurements and isochron precluded derivation of reliable AMA for units older than unit $u c$. 
that the age of Marcia would change if different material strengths are taken into account. In addition, the counting area is found on possible mass wasting materials that formed after the impact.

As a consequence of the impact-dominated surface, impact gardening is clearly an important process acting on the study area and has led to the development of a regolith, as is common on many airless bodies (e.g., Melosh, 1989). For an approximate estimate of the regolith thickness, one can use Marcia crater as a case study. Marcia's ejecta thickness ( 0.2 to $\sim 1.6 \mathrm{~km})$ was determined in Section 4.3. Several impacts similar in dimension to Marcia occurred in the study area, and have produced similar ejecta deposits. The minimal thickness of the regolith formed by these single events can be assumed to be 0.2 to $\sim 1.6 \mathrm{~km}$. Because these craters have formed randomly on the surface, their ejecta has probably accumulated on previously deposited ejecta materials. The final thickness of these ejecta materials is thus greater than that of the single events. Tentatively, the minimum value for the regolith thickness can be estimated at several hundred meters (Jaumann et al., 2012). In addition, the large ruined basins have probably also produced considerable amounts of brecciated material. Beneath the regolith, some more competent material is present, as suggested by spurs (Fig. 10) and boulders. This layer is probably fractured due to the formation of basins and by the Saturnalia Fossae Formation horst-graben system.

\section{Summary}

Data from the Dawn mission have changed our view of Vesta from an astronomical object to a small planetary body that can be studied in geological terms. The northern hemisphere of Vesta was observed by the Dawn Framing Camera with pixel dimensions varying between $20 \mathrm{~m}$ and $560 \mathrm{~m}$, Spatial coverage is nearly global, with only a few pole-ward crater walls remaining in shadow. Using this unique dataset and its derived products (e.g., topography), we have performed the first geological survey of the hemisphere. We have compiled a geologic map and have performed crater size-frequency distribution (CSFD) measurements on the ejecta of fresh craters and for the main geologic units.

On the basis of our mapping, we recognize three fundamental material units: cratered highlands (unit $c h$ ), Saturnalia Fossae trough material (unit Sft) and Saturnalia Fossae cratered material (unit $S f c$ ). Other units mapped in the study areas, as well as elsewhere on Vesta, are bright and dark materials and crater materials. Crater materials have been subdivided into undifferentiated crater material $(u c)$, hummocky crater material $(\mathrm{hcm})$, distant crater material (dicm), lobate crater material (lc), smooth crater floor $(s)$ and crater wall outcrops (cwo).

From CSFD measurements and stratigraphic relationships we infer the following sequence of events that have formed the mapped units. Units $c h, S f t$ and $S f c$ are the oldest units in the map area and are also three of the oldest terrains of Vesta. Unit $c h$ is interpreted as ancient crustal material, similar in surface morphology, topography and CSFDs to the equatorial Vestalia Terra cratered material. If some of the characteristics of the original crust are still recorded on Vesta, they might be best preserved in this unit. Three ruin basins with diameters ranging from $\sim 100$ to $\sim 200 \mathrm{~km}$ were formed, all of which were later affected by unit $S f t$ or unit $S f c$. Tectonic extension due to the Veneneia impact took place in the northern hemisphere and partly affected the preexisting terrain with a horst-graben system (formation of unit Sft). Additional fracturing occurred, possibly as tectonic response to other impacts (unit $S f c$ ). Intense impact bombardment created a highly cratered landscape on these units. The later Rheasilvia impact has potentially created $\mathrm{N}-\mathrm{S}$ linear features such as discontinuous and irregular grooves. Additional impacts that do not follow the isochrones occurred on unit $c h, S f t$ and $S f c$ in the crater diameter range of $\sim 8-11 \mathrm{~km}$. In the last billion years (according to the chronology of Schmedemann et al., in preparation), subsequent impacts created craters $<60 \mathrm{~km}$ in diameter (formation of units $u c$ ). These younger craters display a wide range of degradation states, similar to what is observed in the highly cratered terrains on the Moon. Fresh craters show hummocky and discontinuous ejecta material and strong albedo differences, such as bright rays and dark areas. Potential impact-melt ponds and veneers similar to those observed on the Moon were identified. Gravitationally driven processes such as fine-grained debris avalanches are seen on the walls of fresh craters and create small-scale albedo changes, similar to those observed on other asteroids. In a time span of few tens of million years (according to the chronology of Schmedemann et al., in preparation), space weathering reduced the albedo differences of crater material. Additionally, impact gardening modified the crater shape into muted morphologies. Over hundreds of million years, mass wasting deposits triggered by direct impact or impact shaking covered the crater floors. After several hundred million years, the ejecta material is no longer recognized and the craters appear highly degraded.

In future studies, detailed regolith depth estimates and their variability across the surface would give further insight into surface evolution (Denevi et al., 2012a,b). The analyses of high-resolution images (LAMO) and topography could result in a more comprehensive understanding of small-scale features.

\section{Acknowledgments}

We acknowledge the financial support of the German Aerospace Agency (DLR) (Grant FKZ 50 OW 1102). We also thank the NASA Dawn at Vesta Participating Scientists Program (Grant NNX10AR57G to D.T.B.), as well as DLR-PF and the Max Planck Institute for Solar System Research for the development and operation of the Framing Camera. We would like to thank Paul Helfenstein and an anonymous reviewer for their thorough review of the manuscript.

\section{References}

Arvidson, R. et al., 1978. Standard Techniques for Presentation and Analysis of Crater Size-Frequency Data. NASA Technical Memorandum, 79730.

Ashley, J.W. et al., 2012. Geology of the King crater region: New insights into impact melt dynamics on the Moon. J. Geophys. Res. 117. http://dx.doi.org/10.1029/ 2011JE003990.

Bart, G.D., Melosh, H.J., 2010. Distributions of boulders ejected from lunar craters. Icarus 209, 337-357. http://dx.doi.org/10.1016/j.icarus.2010.05.023.

Bierhaus, E.B., Dones, L., Alvarellos, J.L., Zahlne, K., 2012. The role of ejecta in the small crater populations on the mid-sized saturnian satellites. Icarus $218,602-$ 621. http://dx.doi.org/10.1016/j.icarus.2011.12.011.

Blewett, D.T., Buczkowski, D.L., Ruesch, O., Scully, J.E., O’Brien, D.P., Gaskell, R., Roatsch, T., Bowling, T.J., Ermakov, A., Hiesinger, H., et al., 2014. Vesta's north pole quadrangle Av-1 (Albana): Geologic map and the nature of the south polar basin antipodes. Icarus (submitted for publication)

Bowling, T.J., Johnson, B.C., Melosh, H.J., Ivanov, B.A., 2013. Antipodal topography created by the Rheasilvia impact on Asteroid 4 Vesta. J. Geophys. Res. 118, 1-14. http://dx.doi.org/10.1002/jgre.20123.

Bray, V.J. et al., 2010. New insight into lunar impact melt mobility from the LRO camera. Geophys. Res. Lett. 37 (21). http://dx.doi.org/10.1029/2010GL044666.

Buczkowski, D.L., Barnouin-Jha, O.S., Prockter, L.M., 2008. 433 Eros lineaments: Global mapping and analysis. Icarus 193 (1), 39-52. http://dx.doi.org/10.1016/ j.icarus.2007.06.028

Buczkowski, D.L. et al., 2012. Large-scale troughs on Vesta: A signature of planetary tectonics. Geophys. Res. Lett. 39 (18). http://dx doi.org/10.1029/2012GL052959.

Buczkowski, D.L. et al., 2013a. Brumalia Tholus: An indication of magmatic intrusion on Vesta? Lunar Planet. Sci. 44. Abstract 1996.

Buczkowski, D.L. et al., 2013b. The Geology of Vesta quadrangle Av-9 Numisia: Evaluating the unique geomorphology and physical properties of the Vestalia Terra plateau. Icarus (this issue)

Carr, M.H., Kirk, R.L., McEwen, A., Veverka, J., Thomas, P.H.J.W., 1994. The geology of Gaspra. Icarus 107 (1), 61-71.

Chapman, R.C., 1996. S-type asteroids, ordinary chondrites, and space weathering: The evidence from Galileo's fly-bys of Gaspra and Ida. Meteorit. Planet. Sci. 31, 699-725. 
Clark, B.E. et al., 2001. Space weathering on Eros: Constraints from albedo and spectral measurements of Psyche crater. Meteorit. Planet. Sci. 36, 1617-1637.

Cloutis, E.A., Izawa, M.R.M., Pompilio, L., Reddy, V., Hiesinger, H., Nathues, A., Mann, P., Le Corre, L., Palomba, E., Bell III, J.F., 2013. Spectral reflectance properties of HED meteorites + CM2 carbonaceous chondrites: Comparison to HED grain size and compositional variations and implications for the nature of low-albedo features on Asteroids 4 Vesta. Icarus 223, 850-877. http://dx.doi.org/10.1016/ j.icarus.2013.02.003.

Coradini, A., Turrini, D., Federico, C., Magni, G., 2011. Vesta and Ceres: Crossing the History of the Solar System. Space Sci. Rev. 163 (1-4), 25-40. http://dx.doi.org/ 10.1007/s11214-011-9792-x.

De Sanctis, M.C. et al., 2012a. Spectroscopic characterization of mineralogy and its diversity across Vesta. Science 336 (6082), 697-700. http://dx.doi.org/10.1126/ science. 1219270.

De Sanctis, M.C. et al., 2012b. Detection of widespread hydrated materials on Vesta by the VIR imaging spectrometer on board the Dawn mission. Astrophys. J. 758, L36. http://dx.doi.org/10.1088/2041-8205/758/2/L36.

Denevi, B.W. et al., 2012a. Pitted Terrain on Vesta and Implications for the Presence of Volatiles. Sciencexpress Reports, 20 September. doi: http://dx.doi.org/ $10.1126 /$ science. 1225374 .

Denevi, B.W. et al., 2012b. Regolith depth, mobility, and variability on Vesta from Dawńs low altitude mapping orbit. Lunar Planet. Sci. 43. Abstract 1943.

Dundas, C.M., Keszthelyi, L.P., Bray, V.J., McEwen, A.S., 2010. Role of material properties in the cratering of young platy-ridged lava on Mars. Geophys. Res. Lett. 37, L12203. http://dx.doi.org/10.1029/2010GL042869.

Farquhar, R., Kawaguchi, J., Russell, C.T. Schwehm, G., Veverka, J., Yeomans, D., 2002. Spacecraft exploration of asteroids: The 2001 perspective. In: Bottke, W.F., Jr., Cellino, A., Paolicchi, P., Binzel, R.P. (Eds.), Asteroids III. University of Arizona Press, Tucson, pp. 367-376.

Gaskell, R.W., 2012. SPC Shape and Topography of Vesta from DAWN Imaging Data. American Astronomical Society, DPS Meeting \#44, p. \#209.03.

Gaskell, R.W. et al., 2008. Characterizing and navigating small bodies with imaging data. Meteorit. Planet. Sci. 43, 1049-1061.

Goguen, J., Veverka, J., Thomas, P., Duxbury, T., 1978. Phobos: Photometry and origin of dark markings on crater floors. Geophys. Res. Lett. 5 (11), 981-984.

Greeley, R., Batson, R.M. (Eds.), 1990. Planetary Mapping, Cambridge Planetary Science Series. Cambridge University Press (ISBN 00-521-30774-0).

Hartmann, W.K., Neukum, G., 2001. Cratering chronology and the evolution of Mars. Space Sci. Rev. 96, 165-194. http://dx.doi.org/10.1023/A:1011945222010.

Hausen, K.R., Wilkening, L.L., 1982. Regoliths on small bodies in the Solar System. Annu. Rev. Earth Planet. Sci. 10, 355-376.

Hawke, B.R., Head, J.W., 1977. Impact melt on lunar crater rims. In: Roddy, D.J., Pepin, R.O., Merrill, R.B. (Eds.), Impact and Explosion Cratering. Pergamon Press, New York, pp. 815-841.

Hawke, B.R., Blewett, D.T., Lucey, P.G., Smith, G.A., Bell III, J.F., Campbell, B.A., 2004. The origin of lunar crater rays. Icarus 170, 1-16. http://dx.doi.org/10.1016/ j.icarus.2004.02.013.

Hiesinger, H., Jaumann, R., Neukum, G., Head, J.W., 2000. Ages of mare basalts on the lunar nearside, J. Geophys. Res. 105 (E12). http://dx.doi.org/10.1029/ 2000JE001244.

Hiesinger, H. et al., 2012. How old are young lunar craters? J. Geophys. Res. 117, E00H10. http://dx.doi.org/10.1029/2011JE003935.

Horstman, K.C., Melosh, H.J., 1989. Drainage pits in cohesionless materials: Implications for surface of Phobos. J. Geophys. Res. 94 (B9), 12433-12441.

Hörz, F., Grieve, R., Heiken, G., Spudis, P., Binder, A., 1991. Lunar surface processes. In: Heiken, G., Vaniman, D., French, B.M., Schmitt, J. (Eds.), The Lunar Sourcebook. Cambridge University Press.

Ivanov, B.A., 2001. Mars/Moon cratering rate ratio estimates. Space Sci. Rev. 96, 87104

Jaumann, R. et al., 2012. Vesta's shape and morphology. Science 336 (6082), 687690. http://dx.doi.org/10.1126/science.1219122.

Jutzi, M., Thomas, N., Benz, W., El Maarry, M.R., Jorda, L., Kührt, E., Preusker, F., 2013a. The influence of recent major crater impacts on the surrounding surfaces of (21) Lutetia. Icarus 226, 89-100.

Jutzi, M., Asphaug, E., Gillet, P., Barrat, J.-A., Benz, W., 2013b. The structure of the Asteroid 4 Vesta as revealed by models of planet-scale collisions. Nature 494, 207-210. http://dx.doi.org/10.1038/nature11892.

Kahn, E.G. et al., 2011. A tool for the visualization of small body data. Lunar Planet. Sci. 44. Abstract 1618 .

Keil, K., Stoffler, D., Love, S.G., Scott, E.R.D., 1997. Constraints on the role of impact heating and melting in asteroids. Meteorit. Planet. Sci. 32, 349-363.

Kneissl, T., Van Gasselt, S., Neukum, G., 2011. Map-projection-independent crater size-frequency determination in GIS environments-New software tool for ArcGIS. Planet. Space Sci. 59 (11-12), 1243-1254. http://dx.doi.org/10.1016/ j.pss.2010.03.015.

Kneissl, T., Schmedemann, N., Reddy, V., Williams, D.A., Walter, S., Neesemann, A., Jaumann, R., Krohn, K., Preusker, F., Roatsch, T., et al., 2013. Geology of quadrangle Av-13 Tuccia, Vesta - Morphology and formation ages of mid-sized post-Rheasilvia craters. Icarus (this issue).

Krohn, K. et al., 2013. Bimodal craters on Vesta - Impact on sloping surfaces. Planet. Space Sci. (submitted for publication).

Kumar, P.S. et al., 2013. Gullies and landslides on the Moon: Evidence for drygranular flows. J. Geophys. Res. 118. http://dx.doi.org/10.1002/jgre.20043.

Küppers, M. et al., 2012. Boulders on Lutetia. Planet. Space Sci. 66, 71-78.

Le Corre, L., Reddy, V., Schmedemann, N., Becker, K.J., ÓBrian, D.P., Yamashite, N., Peplowski, P.N., Prettyman, T.H., Li, J.-Y., Cloutis, E.A., et al., 2013. Olivine or impact melt: Nature of the "orange" material on Vesta from Dawn. Icarus 226, $1568-1594$.

Mantz, A., Sullivan, R., Veverka, J., 2004. Regolith transport in craters on Eros. Icarus 167 (1), 197-203. http://dx.doi.org/10.1016/j.icarus.2003.09.023.

Marchi, S. et al., 2012. The violent collisional history of Asteroid 4 Vesta. Science 336 (6082), 690-694. http://dx.doi.org/10.1126/science.1218757.

Marchi, S. et al., 2013. Small crater populations on Vesta. Planet. Space Sci. doi http://dx.doi.org/10.1016/j.pss.2013.05.005 (submitted for publication).

Mayne, R.G., Sunshine, J.M., McSween, H.Y., McCoy, T.J., Corrigan, C.M., Gale, A., 2010. Petrologic insights from the spectra of the unbrecciated eucrites: Implications for Vesta and basaltic asteroids. Meteorit. Planet. Sci. 45 (7), 1074-1092. http://dx.doi.org/10.1111/j.1945-5100.2010.01090.x.

McCord, T., 2006. Ceres, Vesta, and Pallas: Protoplanets, not asteroids. Eos 87 (10) http://dx.doi.org/10.1029/2004JE002244.McCord.

McCord, T.B. et al., 2012. Dark material on Vesta from the infall of carbonaceous volatile-rich material. Nature 491 (7422), 83-86. http://dx.doi.org/10.1038/ nature 11561

McSween, H.Y., Mittlefehldt, D.W., Beck, A.W., Mayne, R.G., McCoy, T.J., 2011. HED meteorites and their relationship to the geology of Vesta and the Dawn mission. Space Sci. Rev. 163 (1-4), 141-174. http://dx.doi.org/10.1007/s11214-010 9637-z.

Melosh, H.J., 1989. Impact cratering a geological process. Oxford Monographs on Geology and Geophysics No. 11. Oxford University Press (ISBN 0-19-504284-0).

Michael, G.G., Neukum, G., 2010. Planetary surface dating from crater sizefrequency distribution measurements: Partial resurfacing events and statistical age uncertainty. Earth Planet. Sci. Lett. 294 (3-4), 223-229. http:// dx.doi.org/10.1016/j.epsl.2009.12.041.

Murray, J.B., Iliffe, J.C., 2011. Morphological and geographical evidence for the origin of Phobos's grooves from HRSC Mars Express images. In: Balme, M.R., Bargery, A.S., Gallagher, C.J., Gupta, S. (Eds.), Martian Geomorphology. Geological Society, London, Special Publications, 356, pp. 21-41.

Neukum, G., Ivanov, B.A., Hartmann, W.K., 2001. Cratering records in the inner Solar System in relation to the lunar reference system. Space Sci. Rev. 96, 55-86. http://dx.doi.org/10.1023/A:1011989004263.

Oberbeck, V.R., 1971. A mechanism for the production of lunar crater rays. Moon 2 (3), 263-278

Osinski, G.R., Tornabene, L.L., Grieve, R.A.F., 2011. Impact ejecta emplacement on terrestrial planets. Earth Planet. Sci. Lett. 310 (3-4), 167-181. http://dx.doi.org/ 10.1016/j.epsl.2011.08.012.

Otto, K.A., Jaumann R., Krohn K., Matz, K.-D., Preusker, F., Roatsch, T., Schenk, P. Scholten, F., Stephan, K., Raymond, C.A., Russell, C.T., 2013. Mass-wasting features and processes in Vestás south polar basin Rheasilvia. J. Geophys. Res. 118. http://dx.doi.org/10.1002/2013JE004333.

Pieters, C.M. et al., 2012. Distinctive space weathering on Vesta from regolith mixing processes. Nature 491 (7422), 79-82. http://dx.doi.org/10.1038/ nature11534.

Plescia, J.B., Cintala, M.J., 2012. Impact melt in small lunar highland craters. J. Geophys. Res. 117. http://dx.doi.org/10.1029/2011JE003941.

Plescia, J.B., Robinson, M.S., 2011. New constraints on the absolute lunar crater chronology. Lunar Planet Sci. 42. Abstract 1839.

Plescia, J.B., Robinson, M.S., Paige, D.A., 2010. Giordano Bruno: The young and the restless. Lunar Planet. Sci. 41. Abstract 2038.

Preusker, F. et al., 2012. Topography of Vesta from Dawn FC stereo images. Lunar Planet. Sci. 43. Abstract 2012.

Prockter, L., Thomas, P., Robinson, M., Joseph, J., Milne, A., Bussey, B., Veverka, J.C.A. 2002. Surface expressions of structural features on Eros. Icarus 155 (1), 75-93. http://dx.doi.org/10.1006/icar.2001.6770.

Quaide, W.L., Oberbeck, V.R., 1968. Thickness determinations of the lunar surface layer from lunar impact craters. J. Geophys. Res. 73, 5247. http://dx.doi.org/ 10.1029/JB073i016p05247.

Rayman, M.D., Fraschetti, T.C., Raymond, C.A., Russell, C.T., 2006. Dawn: A mission in development for exploration of Main Belt asteroids Vesta and Ceres. Acta Astronaut. 58, 605-616. http://dx.doi.org/10.1016/ j.actaastro.2006.01.014

Raymond, C.A. et al., 2013. Vestalia Terra: An ancient mascon in the southern hemisphere of Vesta. Lunar Planet. Sci. 44. Abstract 2882

Reddy, V. et al., 2012a. Color and albedo heterogeneity of Vesta from Dawn. Science 336 (6082), 700-704. http://dx.doi.org/10.1126/science.1219088.

Reddy, V. et al., 2012b. Delivery of dark material to Vesta via carbonaceous chondritic impacts. Icarus 221 (2), 544-559. http://dx.doi.org/10.1016/j.icarus. 2012.08.011.

Roatsch, T., Kersten, E., Matz, K., Preusker, F., Scholten, F., Jaumann, R., 2012. High resolution Vesta High Altitude Mapping Orbit (HAMO) Atlas derived from Dawn Framing Camera images. Planet. Space Sci. 73 (1), 283-286. http://dx.doi.org 10.1016/j.pss.2012.08.021.

Robinson, M.S.M., Thomas, P.C.P., Veverka, J.J., Murchie, S.S., Carcich, B.B., 2001. The nature of ponded deposits on Eros. Nature 413 (6854), 396-400.

Robinson, M.S., Thomas, P., Veverka, J., Murchie, S.L.W.B.B., 2002. The geology of 433 Eros. Meteorit. Planet. Sci. 37, 1651-1684.

Russell, C.T., Raymond, C.A., 2011. The Dawn mission to Vesta and Ceres. Space Sci. Rev. 163 (1-4), 3-23. http://dx.doi.org/10.1007/s11214-011-9836-2.

Russell, C.T. et al., 2006. Dawn mission and operations. In: Lazzaro, D., Ferraz-Mello, S., Fernandez, J.A. (Eds.), Proceedings International Astronomical Union Symposium No. 229, 2005.

Russell, C.T. et al., 2007. Dawn mission to Vesta and Ceres. Earth Moon Planet. 101 (1-2), 65-91. http://dx.doi.org/10.1007/s11038-007-9151-9. 
Russell, C.T. et al., 2012. Dawn at Vesta: testing the protoplanetary paradigm. Science 336 (6082), 684-686. http://dx.doi.org/10.1126/ science. 1219381.

Schenk, P. et al., 2012. The geologically recent giant impact basins at Vesta's south pole. Science 336 (6082), 694-697. http://dx.doi.org/10.1126/science.1223272.

Schorghofer, N., King, C.M., 2011. Sporadic formation of slope streaks on Mars. Icarus 216, 159-168.

Schröder, S.E., Maue, T., Gutiérrez Marqués, P., Mottola, S., Aye, K.M., Sierks, H. Keller, H.U., Nathues, A., 2013a. In-flight calibration of the Dawn Framing Camera. Icarus 226, 1304-1317.

Schröder, S.E., Mottola, S., Keller, H.U., Raymong, C.A., Russell, C.T., 2013b. Resolved photometry of Vesta reveals physical properties of crater regolith. Planet. Space Sci. $85,198-213$.

Schultz, P.H., 1976. Moon Morphology. University of Texas Press.

Scully, J.E., Yin, A., Russell, C.T., Buczkowski, D.L., Williams, D.A., Blewett, D.T. Ruesch, O., Hiesinger, H., Le Corre, L., Garry, W.B., et al., 2014. Saturnalia Fossa group of fossae and additional structures in Vesta's northern hemisphere. Icarus (this issue).

Shoemaker, EM, Batson, R.M. Holt, H.E Morris, E.C, Rennilson, J., Whitaler, EA. 1968. Television Observations from Survey VII, in Surveyor 7 Mission Report. Part 2 - Science Results. Tech. Rep. 32-1264, Jet Propul. Lab. Pasadena, Calif., pp. $9-76$.

Sierks, H. et al., 2011. The Dawn Framing Camera. Space Sci. Rev.. http://dx.doi.org/ 10.1007/s11214-011-9745-4.

Stöffler, D., Ryder, G., 2001. Stratigraphy and isotope ages of lunar geologic units: Chronological standard for the inner Solar System. Space Sci. Rev. 96, 9-54. http://dx.doi.org/10.1023/A:1011937020193.

Sullivan, R. et al., 1996. Geology of 243 Ida. Icarus 120 (1), 119-139. http:// dx.doi.org/10.1006/icar.1996.0041.

Sullivan, R.J., Thomas, P.C., Murchie, S.L., Robinson, M.S., 2002. Asteroid geology from Galileo and NEAR Shoemaker Data. In: Cellino, W.F.B.A., Jr., Paolicchi, P., Binzel, R.P. (Eds.), Asteroids III. University of Arizona Press, pp. 331-350.

Summerfield, M.A., 1991. Global Geomorphology. Pearson Education, Harlow.

Sykes, M.V., Vilas, F., 2001. Closing in on HED meteorite sources. Earth Planets Space $53,1077-1083$

Thomas, P., 1979. Surface features of Phobos and Deimos. Icarus 40, 223-243.

Thomas, P.C., 1989. The shapes of small satellites. Icarus 77 (2), 248-274. http:// dx.doi.org/10.1016/0019-1035(89)90089-4.

Thomas, P.C., Prockter, L.M., 2010. Tectonics of small bodies. In: Watters, T.R. Schultz, R.A. (Eds.), Planetary Tectonics. Cambridge University Press (ISBN 9780-521-76573-2)
Thomas, P.C., Veverka, J., Iii, J.F.B., Clark, B.E., Carcich, B., Joseph, J., Robinson, M., 1999. Mathilde: Size, shape, and geology. Icarus 140 (1), 17-27.

Thomas, P.C. et al., 2000. Phobos: Regolith and ejecta blocks investigated with Mars Orbiter Camera images. J. Geophys. Res. 105 (E6), 15091-15106.

Thomas, P., Joseph, J., Carcich, B., Veverka, J., Clark, B.E., Bell III, J.F., Byrd, A.W.R.C., 2002. Eros: Shape, topography, and slope processes. Icarus 155 (1), 18-37. http://dx.doi.org/10.1006/icar.2001.6755.

Thomas, N. et al., 2012. The geomorphology of (21) Lutetia: Results from the OSIRIS imaging system onboard ESA's Rosetta spacecraft. Planet. Space Sci. 66 (1), 96124. http://dx.doi.org/10.1016/j.pss.2011.10.003.

van der Bogert, C.H. et al., 2010. Discrepancies between crater size-frequency distributions on ejecta and impact melt pools at lunar craters: An effect of differing target properties? Lunar Planet. Sci. 41. Abstract 2165.

van der Bogert, C.H., Hiesinger, H., Krüger, T., McEwen, A.S., Dundas, C., 2013. New evidence for target property influence on crater size-frequency distributions. Lunar Planet. Sci. 44. Abstract 1962.

Veverka, J., Langevin, Y., Farquhar, R., Fulchignoni, M., 1989. Spacecraft exploration of asteroids: The 1988 perspective. In: Asteroids II, pp. 970-993.

Veverka, J. et al., 2001. The landing of the NEAR-Shoemaker spacecraft on Asteroid 433 Eros. Nature 413 (6854), 390-393. http://dx.doi.org/10.1038/35096507.

Watters, T.R., Robinson, M.S., Banks, M.E., Tran, T., Denevi, B.W., 2012. Recent extensional tectonics on the Moon revealed by the Lunar Reconnaissance Orbiter Camera. Nat. Geosci.. http://dx.doi.org/10.1038/NGE01387.

Wilhelms, D.E., McCauley, J.F., Trask, N.J., 1987. The Geologic History of the Moon. USGS Prof. Pap., 1348, p. 302.

Williams, D.A. et al., 2013. Lobate and flow-like features on asteroid Vesta. Planet. Space Sci. doi: http://dx.doi.org/10.1016/j.pss.2013.06.017 (in press).

Williams, D.A., Yingst, R.A., Garry, W.B., 2014a. Introduction: The geologic mapping of Vesta. Icarus (this issue-a).

Williams, D.A., Denevi, B.W., Mittlefehldt, D.W., Mest, S.C., Schenk, P.M., Yingst, R.A Buczkowski, D.L., Scully, J.E.C., Garry, W.B., McCord, T.B., et al., 2014b. The geology of the Marcia quadrangle of asteroid Vesta: Assessing the effects of large, young craters. Icarus (this issue-b).

Yano, H. et al., 2006. Touchdown of the Hayabusa spacecraft at the Muses Sea on Itokawa. Science 312 (5778), 1350-1353. http://dx.doi.org/10.1126/science. 1126164.

Yingst, R.A. et al., 2014. Geologic mapping of Vesta. Planet. Space Sci. (in press). http://dx.doi.org/10.1016/j.pss.2013.12.014.

Zanetti, M., Jolliff, B., van der Bogert, C.H., Hiesinger, H., 2013. New determination of crater size-frequency distribution variation on continuous ejecta deposits: Results from Aristarchus crater. Lunar Planet. Sci. 44. Abstract 1842. 